\title{
Article
}

\section{DJ4 Targets the Rho-Associated Protein Kinase Pathway and Attenuates Disease Progression in Preclinical Murine Models of Acute Myeloid Leukemia}

\author{
Upendarrao Golla ${ }^{1,2, \dagger}$, Melanie A. Ehudin ${ }^{3,+}+{ }^{+}$, Charyguly Annageldiyev ${ }^{1,2}$, Zheng Zeng ${ }^{4}$, Diwakar Bastihalli \\ Tukaramrao $^{3}$, Anna Tarren ${ }^{1,2}$, Abhijit A. Date ${ }^{5}{ }^{(}$, Irina Elcheva ${ }^{3}{ }^{(0)}$, Arthur Berg ${ }^{2}$, Shantu Amin ${ }^{2,4}$, Thomas \\ P. Loughran, Jr. ${ }^{6,7}$, Mark Kester ${ }^{4,7}$, Dhimant Desai ${ }^{2,4}$, Sinisa Dovat ${ }^{3, *}$, David Claxton ${ }^{1,2}$ and Arati Sharma ${ }^{1,2,4, *}$
}

check for updates

Citation: Golla, U.; Ehudin, M.A.; Annageldiyev, C.; Zeng, Z.; Bastihalli Tukaramrao, D.; Tarren, A.; Date, A.A.; Elcheva, I.; Berg, A.; Amin, S.; et al. DJ4 Targets the Rho-Associated Protein Kinase Pathway and Attenuates Disease Progression in Preclinical Murine Models of Acute Myeloid Leukemia. Cancers 2021, 13, 4889. https://doi.org/10.3390/ cancers13194889

Academic Editor: Mary

Frances McMullin

Received: 12 August 2021

Accepted: 22 September 2021

Published: 29 September 2021

Publisher's Note: MDPI stays neutral with regard to jurisdictional claims in published maps and institutional affiliations.

Copyright: (c) 2021 by the authors. Licensee MDPI, Basel, Switzerland. This article is an open access article distributed under the terms and conditions of the Creative Commons Attribution (CC BY) license (https:/ / creativecommons.org/licenses/by/ $4.0 /)$.
1 Department of Medicine, Division of Hematology and Oncology, Pennsylvania State University College of Medicine, Hershey, PA 17033, USA; ugolla@pennstatehealth.psu.edu (U.G.); cannageldiyev@pennstatehealth.psu.edu (C.A.); atarren@pennstatehealth.psu.edu (A.T.); dclaxton@pennstatehealth.psu.edu (D.C.)

2 Penn State Cancer Institute, Pennsylvania State University College of Medicine, Hershey, PA 17033, USA; asb17@psu.edu (A.B.); samin@pennstatehealth.psu.edu (S.A.); ddesai@pennstatehealth.psu.edu (D.D.)

3 Division of Hematology and Oncology, Department of Pediatrics, Pennsylvania State University College of Medicine, Hershey, PA 17033, USA; mehudin@pennstatehealth.psu.edu (M.A.E.); dbastihallitukaramra@pennstatehealth.psu.edu (D.B.T.); ielcheva@pennstatehealth.psu.edu (I.E.)

4 Department of Pharmacology, Pennsylvania State University College of Medicine, Hershey, PA 17033, USA; beigangmm@hotmail.com (Z.Z.); mk5vq@virginia.edu (M.K.)

5 The Daniel K. Inouye College of Pharmacy, University of Hawaii, Hilo, HI 96720, USA; dateabhi@hawaii.edu

6 Department of Medicine, Division of Hematology and Oncology, University of Virginia School of Medicine, Charlottesville, VA 22903, USA; t17cs@virginia.edu

7 Department of Medicine, Division of Hematology and Oncology, University of Virginia Cancer Center, Charlottesville, VA 22903, USA

* Correspondence: sdovat@pennstatehealth.psu.edu (S.D.); asharma@pennstatehealth.psu.edu (A.S.)

+ These authors contributed equally to this work.

Simple Summary: Acute myeloid leukemia (AML) is a rapidly progressing cancer of the blood and bone marrow with high relapse rates. Standard AML treatment has evolved to yield more frequent remission for patients, with little effect on the disease's low five-year survival rate. Patients exhibit a wide variation of molecular alterations, driving efforts to profile patients based on these genetic mutations. Previously, our group developed a novel Rho-associated protein kinase (ROCK) inhibitor, DJ4, and biochemical analysis demonstrated its potency in human cancer cell lines. This work targets the overactive ROCKs, which will help patients that experience abnormalities with ROCK-related processes that have been correlated to various cancers. We provide evidence to support the therapeutic efficacy of DJ4 and indicate its promise to improve AML therapy. Our results indicate that inhibiting ROCK makes AML cells susceptible to cell death and, in leukemia mouse models, reduces disease progression and enhances survival.

Abstract: The poor prognosis of acute myeloid leukemia (AML) and the highly heterogenous nature of the disease motivates targeted gene therapeutic investigations. Rho-associated protein kinases (ROCKs) are crucial for various actin cytoskeletal changes, which have established malignant consequences in various cancers, yet are still not being successfully utilized clinically towards cancer treatment. This work establishes the therapeutic activity of ROCK inhibitor (5Z)-2-5-(1H-pyrrolo [2,3-b]pyridine-3-ylmethylene)-1,3-thiazol-4(5H)-one (DJ4) in both in vitro and in vivo preclinical models of AML to highlight the potential of this class of inhibitors. Herein, DJ4 induced cytotoxic and proapoptotic effects in a dose-dependent manner in human AML cell lines ( $\mathrm{IC}_{50}$ : 0.05-1.68 $\left.\mu \mathrm{M}\right)$ and primary patient cells ( $\mathrm{IC}_{50}: 0.264-13.43 \mu \mathrm{M}$ ); however, normal hematopoietic cells were largely spared. ROCK inhibition by DJ4 disrupts the phosphorylation of downstream targets, myosin light chain (MLC2) and myosin-binding subunit of MLC phosphatase (MYPT), yielding a potent yet selective treatment response at micromolar concentrations, from 0.02 to $1 \mu \mathrm{M}$. Murine models injected with luciferase-expressing leukemia cell lines subcutaneously or intravenously and treated 
with DJ4 exhibited an increase in overall survival and reduction in disease progression relative to the vehicle-treated control mice. Overall, DJ4 is a promising candidate to utilize in future investigations to advance the current AML therapy.

Keywords: Rho-associated protein kinase; acute myeloid leukemia; DJ4; cell line-derived xenograft; primary human AML cells; preclinical AML murine model

\section{Introduction}

Investigations into the malignant hematopoietic transformation (e.g., myeloid cell abnormal proliferation and abnormal differentiation) of acute myeloid leukemia (AML) are of upmost importance given this disease's low overall survival, especially among elderly patients [1,2]. The high death rate is often a result of mutations that form a difficult -to-treat heterogenous tumor microenvironment [1,3]. With the current therapy, AML patients frequently enter remission, but nearly always relapse and tend to develop resistance to most existing standard-of-care treatments (e.g., induction cytotoxic chemotherapy or venetoclax-based therapy) [1,4-6]. Current targeted therapies are directed towards gene mutations found in AML, such as FMS-like tyrosine kinase 3 (FLT3) [7-9], KIT [10,11], BCR-ABL [12], TP53 [13,14], isocitrate dehydrogenase (IDH1 and IDH2) $[1,15,16]$, or mixed lineage leukemia (MLL) [17-19]. Further, targeted therapy is aimed at inhibiting signaling pathways involving aurora kinases (AURKs) [20-22], polo-like kinases (PLKs) [23,24], hedgehog (Hh) [25-27] or Rho kinases (ROCKs) [28-31], or even surface antigens such as CD33 [32] or CD47 [33,34] that tend to be present on myeloid cells. Efforts are ongoing to develop checkpoint inhibitor immunotherapies against programmed death 1 (PD-1) or programmed death ligand 1 (PD-L1) proteins to help stimulate the patient's immune system to fight cancer cells [35]. Despite these innovations, there are many common obstacles to improving the status quo drug regimen and the current prognosis of AML patients. These include establishing whether a therapy is potent enough to inhibit its target to an effective level, optimizing the dosing for effective treatment response while avoiding chemoresistance, determining which drug and/or immunotherapy combination is most efficacious, or evaluating when to administer a certain treatment (better as induction or consolidation therapy). Determining a targeted therapy regimen unique to the patient can be complicated by the time needed to examine the patient's leukemic mutation profile and avoid toxicity to normal hematopoietic and nonhematopoietic tissues in the balance of their disease progression [1].

Interactions between Rho GTPases and the downstream effector, Rho-associated coiled-coil-containing protein kinases (ROCK1 and ROCK2) allow for the phosphorylation of various substrates including the myosin light chain (MLC2) and the myosin-binding subunit of MLC phosphatase (MYPT) which promote actin cytoskeletal changes [36,37]. The Rho-ROCK pathway regulates essential biological processes relating to cell morphology, shape, contraction, migration, adhesion, motility, proliferation, differentiation, cell junction integrity, cell cycle control, and apoptosis [37-40]. This signaling network has established oncogenic roles, with consequences toward tumor development and progression, metastasis, motility, invasion, apoptosis and survival, tumor microenvironment, and angiogenesis [39,41-44]. Recent advances have also explored utilizing short interfering RNA (siRNA)- or short hairpin RNA (shRNA)-based gene silencing methods to further understand the role of ROCK in various diseases [39,42,45]. However, due to its broad functionality and the high overall identity between the ROCK1 and ROCK2 isoforms, studies are still needed to fully understand its advantageous or disadvantageous roles in these signaling pathways, complicating selective ROCK inhibition drug development. Further, current ROCK inhibitors such as Fasudil or Y27632 (not used as the current standard of care cancer treatment) tend to have multikinase activity and therefore may have potential off-target effects $[39,41,43,46]$. Thus, recent advances are aimed at not only designing 
more selective inhibitors, but also at developing appropriate chemotherapeutics to use in combination to support clinical utility of these ROCK inhibitors towards various cancers $[39,41,43,46,47]$. There is also a need for further preclinical studies of ROCK inhibitor anticancer therapy to determine which cancers (e.g., tumor cell type and microenvironment) or which types of patients this treatment would be most efficacious for and to establish pharmacodynamic or characteristic biomarker endpoints of treatment $[39,41]$.

Targeting several areas of a signaling cascade or multiple kinases with similar functions can provide a more efficacious treatment, one that is less susceptible to chemoresistance; for instance, ROCK and MRCK combined inhibition has been previously reported to be more potent in inhibiting actomyosin-regulated functions [41,48,49]. Additionally, lung cancer cell line A549 and breast cancer cell line MDA-MB-231 have been shown to be sensitive to DJ4 [50]. Western blotting, kinase functional/cellular activity, and computational assays indicated DJ4 selectively acts as an ATP competitive inhibitor of the kinases ROCK1/2 and MRCK $\alpha / \beta$, which are responsible for the processes needed for cancer cell migration/invasion [50]. These findings indicate the promising therapeutic potential of DJ4 in vitro in human lung and breast cancer cell lines [50]; however, in vitro and vivo efficacy in AML has not been pursued.

Herein, continuing efforts to thoroughly examine the therapeutic efficacy of (5Z)2-5-(1H-pyrrolo[2,3-b] pyridine-3-ylmethylene)-1,3-thiazol-4(5H)-one (DJ4), a ROCK and myotonic dystrophy kinase-related Cdc42-binding kinase (MRCK) inhibitor [50], towards acute myeloid leukemia are presented. We describe cell proliferation and colony formation assays followed by preclinical murine therapeutic studies to gauge the potency of DJ4 towards various AML cell lines. AML patient-derived samples were also studied to determine whether the treatment prevents tumor formation or progression towards a heterogenous lineage which is characteristic of this disease. Further, apoptotic assays, Western blotting, and flow cytometry analysis were performed to gain molecular insight into the downstream processes and therapeutic benefit achieved by DJ4. This work highlights the potential of targeting the Rho-ROCK pathway to improve the prognosis of AML. The experiments herein present an analysis to establish a ROCK inhibitor, thereby laying the fundamental groundwork needed for the future development of chemotherapeutics that are both less toxic and more effective.

\section{Materials and Methods}

\subsection{Cells and Cell Culture}

The human AML-derived cell lines HL-60 (CCL-240), MV4-11 (CRL-9591) were obtained from the American Type Culture Collection (ATCC), Manassas, VA, USA. All the other cell lines such as OCI-AML2, OCI-AML3, MOLM-13, and U937 were provided to us as mentioned in the acknowledgments. Cell lines utilized in this study were authenticated by short tandem repeat (STR) profiling. Bone marrow aspirates or peripheral blood samples were acquired from AML patients, and cord blood (CB) samples were obtained from freshly delivered placentas of healthy donors after informed consent using protocols approved by the Institutional Review Board of the Penn State College of Medicine. Mononuclear cells (MNC) were isolated by means of density gradient separation (Ficol-Paque, GE Healthcare Life Sciences, Pittsburgh, PA, USA). Cell lines and primary cells were cultured as previously described [51,52]. DJ4 was synthesized previously at the Organic Synthesis Core of the Penn State College of Medicine, and its high purity (>99\%) was quantified via high-performance liquid chromatography and nuclear magnetic spectroscopy [50]. DJ4 was dissolved in dimethyl sulfoxide (DMSO) and filtered through a 0.22-micron filter prior to cell or animal treatment. The percentage of DMSO was $<0.01 \%$ for the in vitro assays.

\subsection{Cell Viability Assay}

The cells were seeded at a constant density in a 96-well plate and treated with increasing concentrations of DJ4 (0.001-20 $\mu \mathrm{M})$ for $24 \mathrm{~h}$. Each concentration was tested in triplicate within the plate. The relative viability and $\mathrm{IC}_{50}$ were measured using the MTS [3- 
(4,5-dimethylthiazol-2-yl)-5-(3-carboxymethoxyphenyl)-2-(4-sulfophenyl)-2H-tetrazlium, inner salt] assay (CellTiter 96 Aqueous One Solution Cell Proliferation Assay, Promega, Madison, WI, USA) according to the manufacturer's protocol and the data were analyzed using the GraphPad Prism 6.0 software (GraphPad Software, San Diego, CA, USA). Baseline absorbance at $490 \mathrm{~nm}$ was subtracted from the data and normalized to the controls. Cytotoxicity experiments were conducted in three independent trials to ensure reproducibility.

\subsection{Apoptotic and Cell Cycle Assays}

The cells were plated at a constant seeding density and treated with increasing concentrations of DJ4 $(0-20 \mu \mathrm{M})$ for $24 \mathrm{~h}$. The percentage of apoptosis in AML cells was detected using the combination of the AnnexinV-PE (BD Biosciences, Franklin Lakes, NJ, USA) and 7-AAD (BioLegend, San Diego, CA, USA) dyes. Additionally, the cells were fixed with ethanol after $24 \mathrm{~h}$ treatment with DJ4 for cell cycle analysis using the FxCycle ${ }^{\mathrm{TM}}$ PI/RNase Staining Solution (Thermo Fisher Scientific, Waltham, MA, USA). The data for apoptosis and cell cycle analysis were acquired using a BD Accuri ${ }^{\mathrm{TM}} \mathrm{C} 6$ Plus instrument. The relative apoptosis of the primary AML patient cells was determined by resuspending and incubating the cells using the Muse Annexin V \& Dead Cell Kit (MCH100105, Millipore, Burlington, MA, USA) according to the manufacturer's protocol. The values were obtained using a benchtop flow cytometer, Muse Cell Analyzer (Millipore Sigma).

\subsection{Colony-Forming Assay}

The cells were cultured at a constant optimal seeding density in Human Methylcellulose Base Media (R\&D Systems, Minneapolis, MN, USA) in a 12-well plate to yield colony outgrowth of 20-100 colonies per well as described previously [51,52]. To test the clonogenic potential, the cells were cultured in the presence of increasing concentrations of DJ4 $(0-10 \mu \mathrm{M})$ or the DMSO vehicle in a methylcellulose medium for 7-14 days. Blast colonies ( $>20$ cells/colony) were counted under a light microscope and imaged with an Olympus CKX31 inverted microscope (Olympus Corporation, Center Valley, PA, USA) using a $4 \times$ objective.

\subsection{Western Blot Analysis}

The AML cell line (MV4-11 and OCI-AML3) cells were treated with increasing concentrations of DJ4 $(0-1 \mu \mathrm{M})$ or DMSO and harvested at $24 \mathrm{~h}$. Whole cell lysates were then collected in a RIPA buffer (Sigma) containing phosphatase and protease inhibitor cocktails (Sigma). Protein quantification was performed using a bicinchoninic acid (BCA) assay kit (Pierce, Thermo Fisher Scientific, Waltham, MA, USA). Denatured protein samples run on a NuPAGE 4-12\% Bis-Tris gel (Life Technologies, Carlsbad, CA, USA) were subsequently probed with various primary antibodies as previously described [51,52]. Bands were detected using the Bio-Rad ChemiDoc MP imaging system (Bio-Rad Laboratories, Hercules, CA, USA) and quantified via the ImageJ software [53]. The following antibodies were obtained: ROCK1 (611136; BD Biosciences), ROCK2 (610623; BD Biosciences), MYPT1 (07-672-I; Millipore Sigma), Phospho-MYPT1 (Thr696) (5163S; Cell Signaling Technology, Danvers, MA, USA), MLC2 (3672S; Cell Signaling Technology), Phospho-MLC2 (PA517726; Thermo Scientific), and GAPDH (sc-32233; Santa Cruz Biotechnology, Dallas, TX, USA); the goat anti-rabbit IgG-horseradish peroxidase (HRP) conjugates and the horse anti-mouse IgG-HRP conjugates were purchased from Cell Signaling Technology. All the whole western blot figures can be found in the Figure S9.

\subsection{Preclinical Murine Studies}

Toxicity, dosing, and route of DJ4 were assessed by treating B6(Cg)-Tyr ${ }^{c-2 J} / \mathrm{J}$ (Albino B6) mice (The Jackson Laboratory, Bar Harbor, ME, USA) with DJ4 and monitoring body weight, survival, and overt signs of illness. The mice were administered the vehicle DMSO $(n=5)$ or a solution of DJ4 in DMSO $(10 \mathrm{mg} / \mathrm{kg}, n=5)$ intraperitoneally (I.P.) for 2.5 weeks. The animals were then euthanized, and blood was collected via cardiac 
puncture for complete blood count $(\mathrm{CBC})$ with differential and chemistries. The $\mathrm{CBC}$ with differential measured the levels of white blood cells (WBCs), red blood cells (RBCs), hemoglobin ( $\mathrm{Hgb})$, hematocrit (HCT), mean corpuscular volume (MCV), mean corpuscular hemoglobin $(\mathrm{MCH})$, mean corpuscular hemoglobin concentration (MCHC), and platelets. The metabolic panel consisted of the following tests: glucose (GLU), creatinine (CREA), blood urea nitrogen (BUN), phosphorus (PHOS), calcium (CA), total protein (TP), albumin (ALB), alanine aminotransferase (ALT), alkaline phosphatase (ALKP), total bilirubin (TBIL), total cholesterol (CHOL), and amylase (AMYL). Cross-sections of the spleen, liver, lung, and kidney were formalin-fixed and paraffin-embedded to assess tissue morphology with hematoxylin and eosin (H\&E) staining. Images of the tissue morphology and the stained section were captured using Nikon Eclipse Ts2R (Nikon, Melville, NY, USA).

Pharmacokinetic data of DJ4 were established by intraperitoneally treating 21 albino B6 mice with DJ4 $(10 \mathrm{mg} / \mathrm{kg})$ and collecting blood via cardiac puncture from three mice at each of the following time points: $0.25,0.5,1,3,6,12$, and $24 \mathrm{~h}$. Blood was processed to isolate the serum and then submitted for mass spectrometry analysis to quantify the circulating concentration of DJ4 in the blood over time.

Cell line-derived xenograft (CDX) models were established with OCI-AML3-yellow fluorescent protein (YFP)-luciferase (Luc) and MV4-11-Luc2-enhanced green fluorescent protein (EGFP). The luciferase-expressing leukemia cell lines were subcutaneously (S.C., $2-2.5 \times 10^{6}$ cells) or intravenously (I.V., 2-2.5 $\times 10^{6}$ cells) administered to 8-12-weekold NOD.Cg-Rag1 ${ }^{\text {tm1Mom }}$ Il2rg ${ }^{\text {tm } 1 \text { Wjl }} \mathrm{Tg}$ (CMV-IL3,CSF2,KITLG)1Eav/J (NRG-S) mice (The Jackson Laboratory, Bar Harbor, ME, USA) and the disease progression was monitored with bioluminescence imaging (BLI) as previously established [51,52]. The mice were randomized based on the BLI signal, segregated into either control or treatment groups, and intraperitoneally treated with DMSO or DJ4 $(10 \mathrm{mg} / \mathrm{kg})$ for 3 weeks. The in vivo studies initially included extra mice, with outliers in engraftment being removed, to ensure no variability in the leukemia burden among the mice within the control and DJ4 groups prior to randomization. Treatment was performed in a continuous cycle administering DJ4 once a day for five days followed by a two-day break. The murine studies were repeated at least twice. Whole-body leukemic burden was quantified using the Living Image software (Perkin Elmer). Overall survival was monitored, and Kaplan-Meier analysis was carried out. Over the course of the study (subcutaneous model studies), the tumor volume $\left(\mathrm{mm}^{3}\right)$ was measured with calipers, and towards the conclusion of the study, the tumors were isolated and weighed $(\mathrm{g})$.

The luciferase-labeled cell lines were also treated with DMSO or their respective $\mathrm{IC}_{50}$ dose of DJ4 for $24 \mathrm{~h}$ and administered intravenously to the NRG-S mice. The mice injected with the pretreated cells were then monitored without further treatment, and similar imaging and survival analysis was performed. Bone marrow and spleen tissues were additionally harvested from the DMSO and DJ4 pretreated groups and analyzed for engraftment by flow cytometry. The tissues harvested from the murine studies were evaluated by staining for GFP expression, APC-Cy7-labeled anti-human CD45 (hCD45, BioLegend), mouse CD45-BV650 (mCD45, BD Bioscience, Billerica, MA, USA), and dead cell exclusion dye, 7AAD (BioLegend). The data were collected by means of flow cytometry using a BD LSR II flow cytometer and analyzed via the FlowJo software [54].

All the animal experiments were conducted at the Penn State University College of Medicine under protocols approved by the Institutional Animal Care and Use Committee at Penn State, Hershey, PA, USA (IACUC \# PROTO201246746).

\subsection{Statistical Analysis}

Statistical analysis was performed by means of the $t$-test, Gehan-Breslow-Wilcoxon test, or two-way analysis of variance (ANOVA) utilizing the GraphPad Prism 6.0 software (GraphPad Software, San Diego, CA, USA). All the findings reported herein were repeated in at least two independent experiments and are the means \pm standard error of the mean 
(SEM) or standard deviation (SD), wherein $p<0.05$ (95\% CI) is considered statistically significant; $p$-values or asterisks denote the data that were statistically significant.

\section{Results}

\subsection{DJ4 Exerts Cytotoxic Activity in AML Cell Lines and Primary Cells}

ROCK1 overexpression has been linked to AML cell lines and overall survival of AML patients, suggesting that ROCK inhibition may mediate leukemic cell death and improve conventional AML therapeutics (Figures S1 and S2). To determine the cytotoxic effect of DJ4 (Figure 1A) on AML cells in vitro, several human leukemic cell lines (MOLM-13, MV4-11, OCI-AML2, OCI-AML3, HL-60, and U937) and AML patient samples were chosen. The cell proliferation and relative viability were measured after treatment with DJ4 $(0.001-20 \mu \mathrm{M})$ for $24 \mathrm{~h}$. For all the AML cell lines, as the concentration of DJ4 was increased, the relative viability decreased in a dose-dependent manner (Figure 1B). The half-inhibitory concentration $\left(\mathrm{IC}_{50}\right.$ ) values for the cell lines were between 0.05 and $1.68 \mu \mathrm{M}$ (Figure $1 \mathrm{C}$ and Table S1). MV4-11 was the most sensitive AML cell line to drug treatment $\left(\mathrm{IC}_{50}=0.05 \pm 0.02 \mu \mathrm{M}\right)$, followed by MOLM-13 $\left(\mathrm{IC}_{50}=0.15 \pm 0.03 \mu \mathrm{M}\right)$, OCI-AML2 $\left(\mathrm{IC}_{50}=0.63 \pm 0.07 \mu \mathrm{M}\right), \mathrm{OCI}-$ AML3 $\left(\mathrm{IC}_{50}=0.81 \pm 0.12 \mu \mathrm{M}\right)$, and HL-60 $\left(\mathrm{IC}_{50}=0.93 \pm 0.05 \mu \mathrm{M}\right)$ (Figure 1B and Table S1). The cell line with no specific AML molecular signature, U937, was the least responsive $\left(\mathrm{IC}_{50}=1.68 \pm 0.70 \mu \mathrm{M}\right)$ to DJ4 treatment.

DJ4 treatment inhibited the colony-forming ability of the AML cell lines (Figure 1D,E) and the primary patient cells (Figure 2) in the micromolar range and a dose-dependent manner. Drug treatment was able to inhibit the number of colonies, particularly of MV411 and MOLM-13, wherein approximately half the number of colonies were observed relative to the untreated cells with $0.3 \mu \mathrm{M}$ DJ4 treatment (Figure 1D,E). A reduction in the colony-forming ability of U937 by $\sim 40-50 \%$ required $1-3 \mu \mathrm{M}$ DJ4 treatment. The AML primary cells had a marked decrease in the colony-forming ability with increasing DJ4 treatment (Figure 2). The $\mathrm{IC}_{50}$ values of DJ4 for the cord blood mononuclear cells (CBMNCs) and the AML primary cells were extrapolated from the colony-forming assay and found to range from 0.26 to $25 \mu \mathrm{M}$ (Figure $2 \mathrm{C}$ and Table 1 ). In the presence of $0.5 \mu \mathrm{M}$ DJ4 treatment, AML patient samples $1265\left(\mathrm{IC}_{50}=0.50 \mu \mathrm{M}\right)$ and $990\left(\mathrm{IC}_{50}=0.26 \mu \mathrm{M}\right)$ exhibited a considerable reduction of $\sim 50 \%$ in the number of colonies relative to the untreated cells (Figure 2A). The other AML patient samples such as $1241\left(\mathrm{IC}_{50}=2.77 \mu \mathrm{M}\right), 1172$ $\left(\mathrm{IC}_{50}=5.06 \mu \mathrm{M}\right), 1103\left(\mathrm{IC}_{50}=5.17 \mu \mathrm{M}\right), 1044\left(\mathrm{IC}_{50}=5.14 \mu \mathrm{M}\right), 1290\left(\mathrm{IC}_{50}=5.62 \mu \mathrm{M}\right)$, and $1341\left(\mathrm{IC}_{50}=5.77 \mu \mathrm{M}\right)$ needed higher concentrations of DJ4 $(2.5-5 \mu \mathrm{M})$ to impact the number of colonies (Figure 2A, Table 1$)$. AML patient sample $1099\left(\mathrm{IC}_{50}=13.43 \mu \mathrm{M}\right)$ required 10 $20 \mu \mathrm{M}$ DJ4 to affect its colony-forming ability significantly. However, treatment with DJ4 imparted a considerable effect on the AML patient cells relative to the CB-MNCs of the healthy donor cells $\left(\mathrm{IC}_{50}=25 \mu \mathrm{M}\right.$ ) (Figure 2B,C, Table 1). DJ4 was $\sim 5$-fold more selective towards the AML primary cells compared to the primary CB-MNCs (Figure 2B,C, Table 1). 
A.<smiles>O=C1N/C(=N\CCc2ccccc2)S/C1=C/c1c[nH]c2ncccc12</smiles>

$$
\begin{gathered}
\text { DJ4 } \\
\mathrm{C}_{19} \mathrm{H}_{16} \mathrm{~N}_{4} \text { OS }
\end{gathered}
$$$$
348.42 \mathrm{~g} / \mathrm{mol}
$$

c.

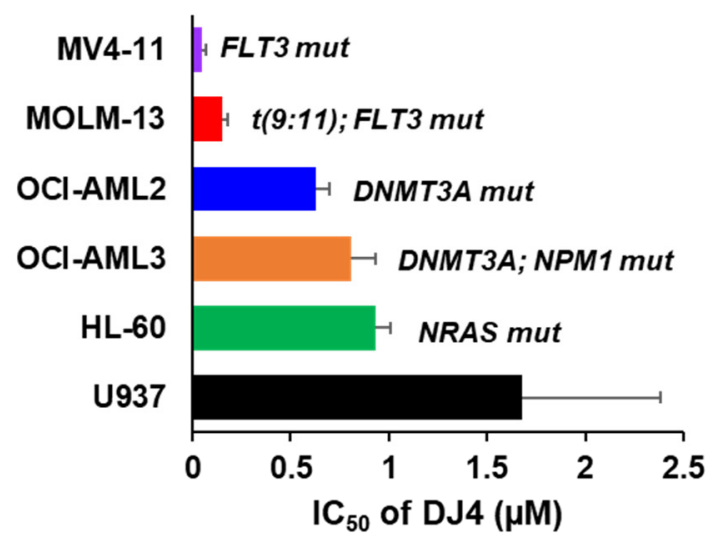

E.

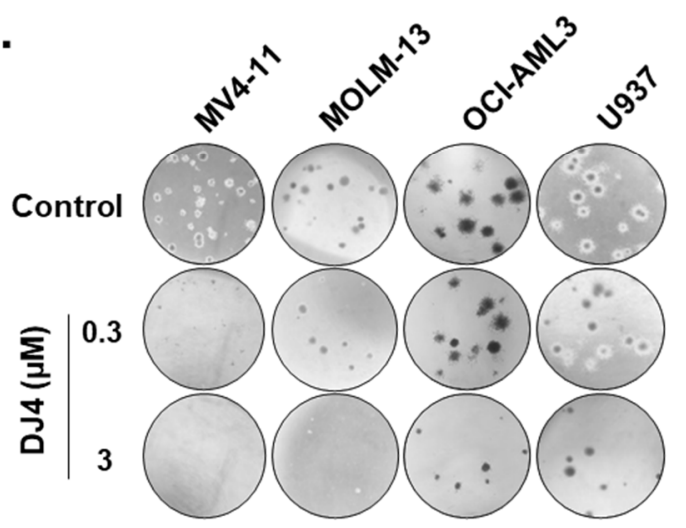

B.

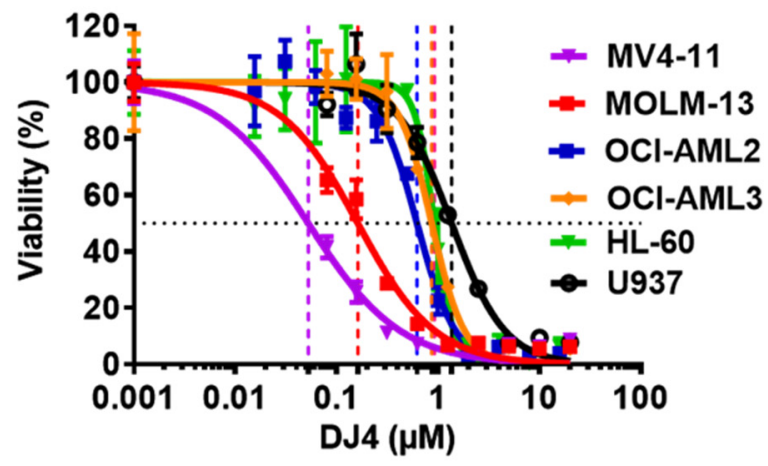

D.

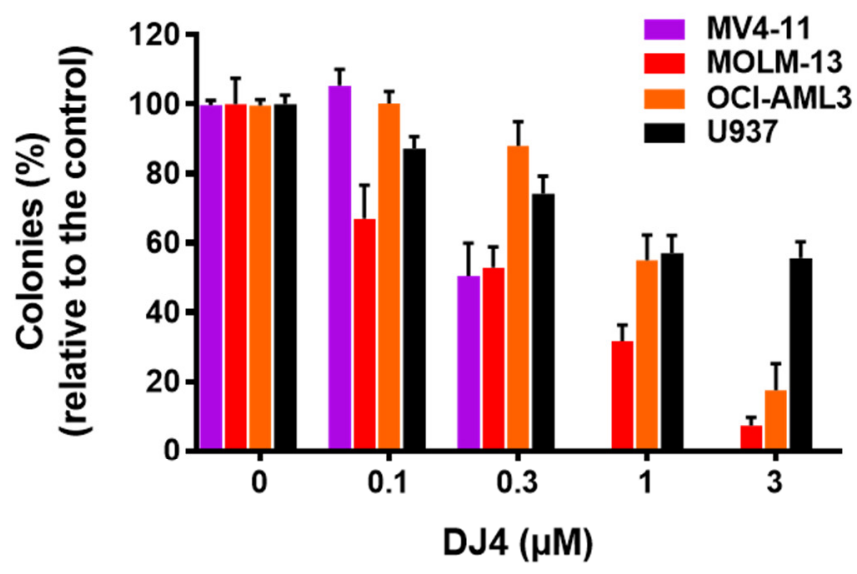

Figure 1. Human AML cell lines are sensitive to DJ4 treatment. (A) Chemical structure of DJ4. (B) Cytotoxic drug response measured using the MTS assay upon DJ4 treatment for $24 \mathrm{~h}$ on various human AML cell lines. (C) Corresponding IC 50 ( $\mu \mathrm{M})$ values from the MTS assay indicative of the sensitivity of cells with various AML-specific mutations to DJ4. (D) Colonyinhibiting capability of DJ4 on AML cell lines. (E) Microscopic images $(4 \times)$ of the DJ4-mediated effect on clonogenicity of AML cell lines in a colony growth medium. The data are the means \pm standard deviation (SD). 


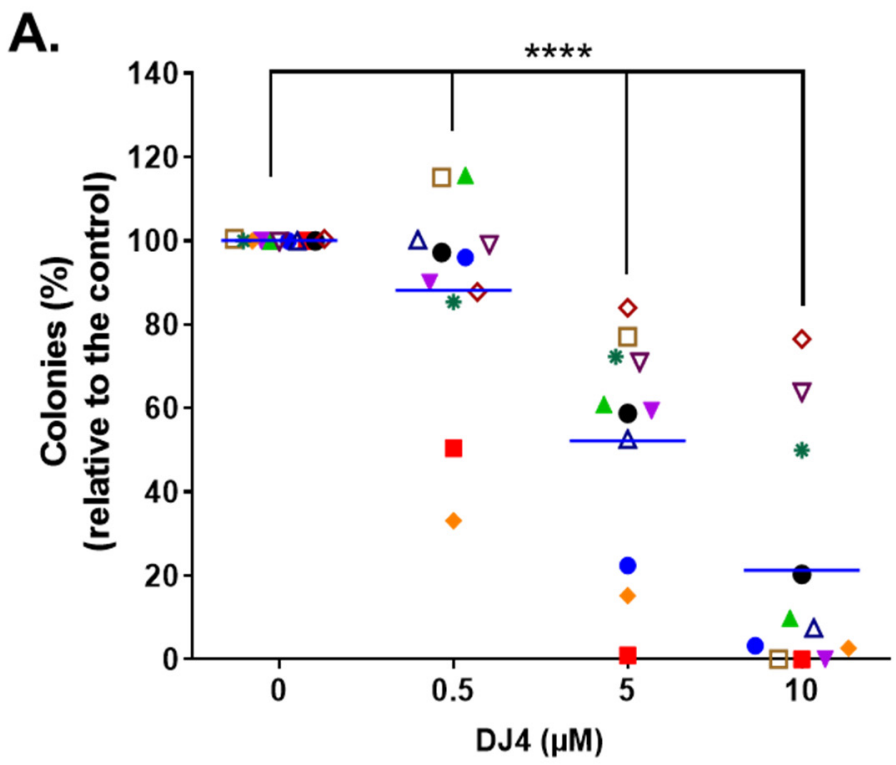

- Pt. 1241

- Pt. 1265

A Pt. 1290

$\checkmark$ Pt. 1172

- Pt. 990

- Pt. 1341

口 Pt. 1103

$\Delta$ Pt. 1044

* Pt. 1099

$\nabla$ CB-MNCs \#1

$\diamond$ CB-MNCs \#2

B.

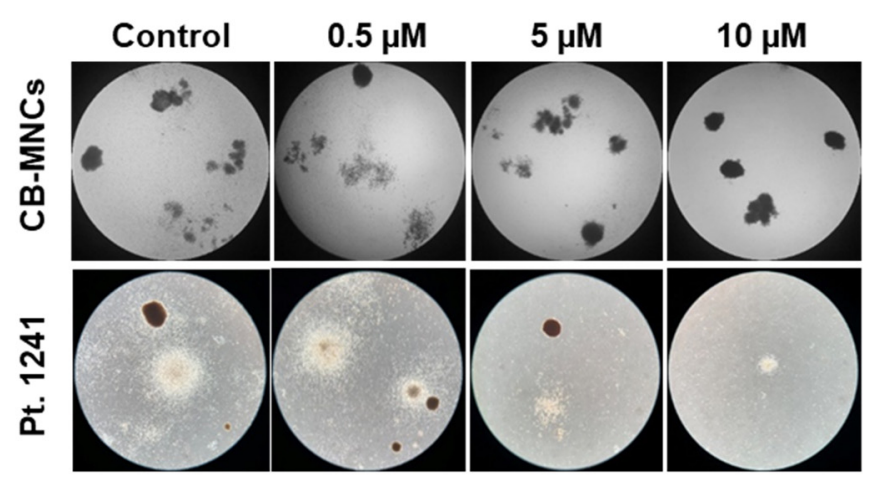

c.

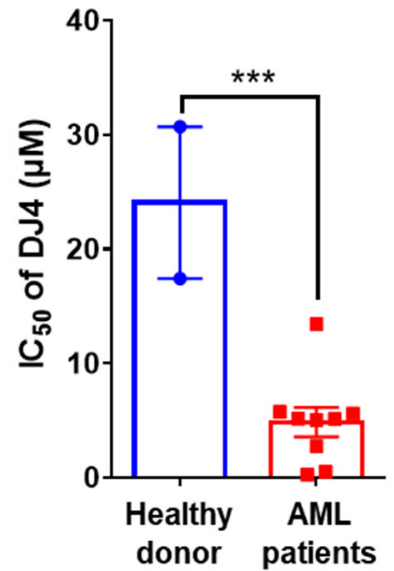

Figure 2. DJ4 reduces clonogenicity in AML patient samples while sparing healthy donor cells. (A) Clonogenicity of the primary AML samples relative to the cord blood mononuclear cells (CB-MNCs) in the presence of DJ4. The data were analyzed via two-way ANOVA (Dunnett's multiple comparisons test) to compare the grand mean colonies, shown with a blue line, of DJ4 treatment versus the control colonies, wherein ${ }^{* * * *} p<0.0001$ was considered significant. (B) Representative microscopic images $(4 \times)$ illustrating the number of colonies with increasing DJ4 concentrations in AML primary patient sample 1241 versus the control CB-MNCs. (C) Extrapolation of the $\mathrm{IC}_{50}(\mu \mathrm{M})$ values from the colony-forming assay in $(\mathrm{A})$. The results were assessed by means of the unpaired $t$-test and ${ }^{* * *} p<0.001$ was considered significant. The data are the means \pm SEM.

Table 1. AML patient information and the corresponding $\mathrm{IC}_{50}(\mu \mathrm{M})$ values for DJ4.

\begin{tabular}{|c|c|c|c|c|c|c|}
\hline Code & Age & Gender & $\begin{array}{c}\text { WBC } \\
(\times 10,000 / \mu \mathrm{L})\end{array}$ & Cytogenetics & Molecular Data & $\begin{array}{c}\mathrm{DJ} 4 \\
\mathrm{IC}_{50}(\mu \mathrm{M})\end{array}$ \\
\hline 990 & 69 & M & 106.66 & 46,XY,del(13)(q12q14)[2]/46,XY[18] & U2AF1 & 0.264 \\
\hline 1265 & 74 & M & 217.36 & $46, \mathrm{XY}, \mathrm{t}(7 ; 11)(\mathrm{p} 15 ; \mathrm{p} 15)$ & FLT3-ITD, HOXA9/NUP98 FUSION & 0.504 \\
\hline 1241 & 50 & $\mathrm{~F}$ & 180.40 & $46, X X$ & NPM1, FLT3-ITD & 2.769 \\
\hline 1172 & 46 & $\mathrm{~F}$ & 149.23 & $46, X X$ & FLT3-ITD & 5.055 \\
\hline 1044 & 70 & M & 36.4 & $\begin{array}{c}\begin{array}{c}46, \mathrm{XY}, \mathrm{i}(17)(\mathrm{q} 10)[12] / 47, \mathrm{idem},+13[2] / 47, \mathrm{XY} \\
+\operatorname{mar}[6]\end{array}\end{array}$ & $\begin{array}{l}\text { CBL, APC, SALL4, ASXL1, SETBP1, } \\
\text { SRSF2, FLT3-ITD, ESCO2 }\end{array}$ & 5.142 \\
\hline 1103 & 41 & $\mathrm{~F}$ & 247.25 & $46, X X$ & FLT3-ITD, NOTCH1, PTPN11 & 5.167 \\
\hline 1290 & 74 & M & 99.07 & $46, X Y$ & $\begin{array}{l}\text { ASXL1, DNMT3A, IDH1, KRAS, } \\
\text { NRAS, RUNX1 }\end{array}$ & 5.616 \\
\hline 1341 & 83 & M & 201.00 & $\begin{array}{c}46, X Y, t(1 ; 3)(p 34.1 ; q 27) \\
\mathrm{t}(2 ; 18)(\mathrm{q} 31 ; \mathrm{q} 11.2), \operatorname{del}(11)(\mathrm{p} 11.2 \mathrm{p} 15)\end{array}$ & CBL, KIT & 5.765 \\
\hline 1099 & 86 & M & 141.02 & $46, X Y$ & $\mathrm{~N} / \mathrm{A}$ & 13.430 \\
\hline
\end{tabular}




\subsection{DJ4 Induces Apoptosis in AML Cell Lines and Primary Cells}

Treatment of DJ4 after $24 \mathrm{~h}$ on the AML cell lines and the primary AML patient samples induced apoptosis within the micromolar range in a dose-dependent manner (Figure 3 and Figures S3 and S4). MOLM-13 was considerably more sensitive to DJ4 treatment, wherein higher percentage of apoptosis was observed in the presence of 0.3$1.8 \mu \mathrm{M}$ DJ4, than the other AML cell lines (Figure 3A). Exposure to low concentrations, 0.3 and $0.6 \mu \mathrm{M}$, of DJ4 induced about $40 \%$ and $70 \%$ apoptosis in MOLM-13, respectively. The other AML cell lines required higher DJ4 concentrations to exert the same apoptotic effect. MV4-11 needed 0.6-1.2 $\mu \mathrm{M}$ DJ4 treatment, whereas OCI-AML3 and U937 required exposure to $1.2-1.8 \mu \mathrm{M}$ DJ4 to lead to $\sim 50 \%$ apoptosis (Figure $3 \mathrm{~A}$ ). Cell cycle analysis also demonstrated the impact of DJ4 in the OCI-AML3, MV4-11, and MOML-13 cells to induce cell death via apoptosis by the dose-dependent increase in the sub-G0/G1 cell population with increasing concentrations of the drug (Figure S3). Exposure to DMSO or 0.05, 0.15, 0.3, and $0.6 \mu \mathrm{M}$ DJ4 of the MV4-11 cells resulted in an increase in the sub-G0/G1 population by $2.90,3.50,4.61,9.55$, and $11.9 \%$, respectively (Figure S3A,B). DJ4 enhanced the G0/G1 cell death phase in the MOLM-13 cells by $3.46,8.63,9.37$, and $11.40 \%$ with $0.15,0.3,0.6$, and $1.2 \mu \mathrm{M}$ drug treatment, respectively (Figure S3C,D). Treatment with $0.3,0.6$, and $1.2 \mu \mathrm{M}$ DJ4 in OCI-AML3 resulted in a greater sub-G0/G1 population by $2.03,3.16$, and $8.28 \%$, respectively (Figure S3E,F). A significant change in the apoptotic population was observed in the cell cycle assay with $1.2 \mu \mathrm{M}$ DJ4 treatment of OCI-AML3, whereas exposure to only $0.3 \mu \mathrm{M}$ DJ4 was needed to induce a greater apoptotic response in the MV4-11 and MOLM-13 cell lines. This is comparable to the results observed with the MTS and colonyforming assays, wherein MV4-11 and MOLM-13 were more sensitive than OCI-AML3 towards DJ4. The AML cell lines tended to be more sensitive to DJ4 treatment as observed in the cytotoxicity and colony-forming assays requiring less DJ4 to induce $50 \%$ apoptosis versus the AML primary cells (Figure 3 and Figure S4). Representative flow cytometry plots of the Annexin V assay with the AML primary cells shown in Figure 3B depict the dose-dependent increase in the apoptotic populations of AML primary sample 1265 as a result of treatment with increasing concentrations of DJ4 (Figure 3C). AML patient sample 990 was the most responsive, with a greater percentage of apoptosis, $30-40 \%$, observed relative to the untreated cells, with low concentrations of DJ4 treatment $(0.5-1 \mu \mathrm{M})$ than the other AML primary cases (Figure 3B and Figure S4). This is consistent with the colony forming data where patient samples 990 and 1265 were the most sensitive to DJ4 treatment. Treatment with low concentrations of DJ4 $(0.5-1 \mu \mathrm{M})$ induced $10-20 \%$ apoptosis versus the untreated cells in AML primary samples 1172, 1099, 1290, and 1341. Treatment with $5 \mu \mathrm{M}$ of DJ4 stimulated $\sim 30-50 \%$ apoptosis relative to the untreated cells in all the AML primary samples (Figure 3B,C and Figure S4). The apoptotic effect of $10-20 \mu \mathrm{M}$ versus $5 \mu \mathrm{M}$ DJ4 treatment was not vastly different among the AML primary samples (Figure 3B,C and Figure S4). 
A.

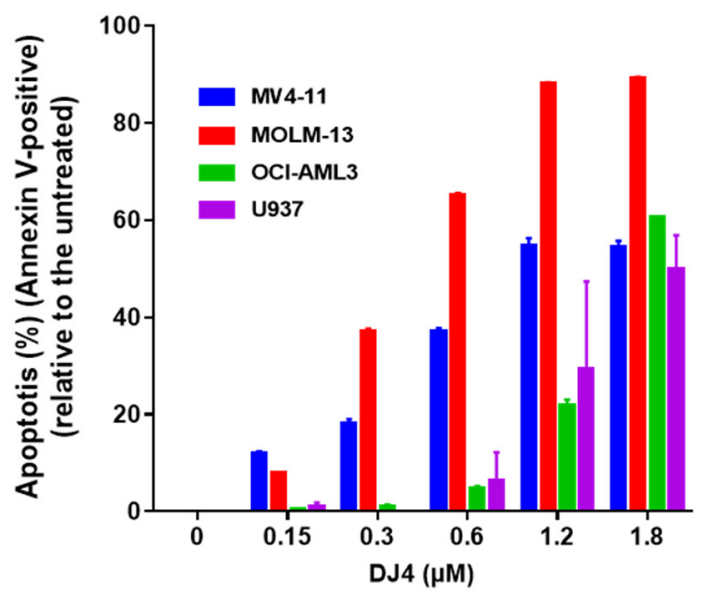

B.

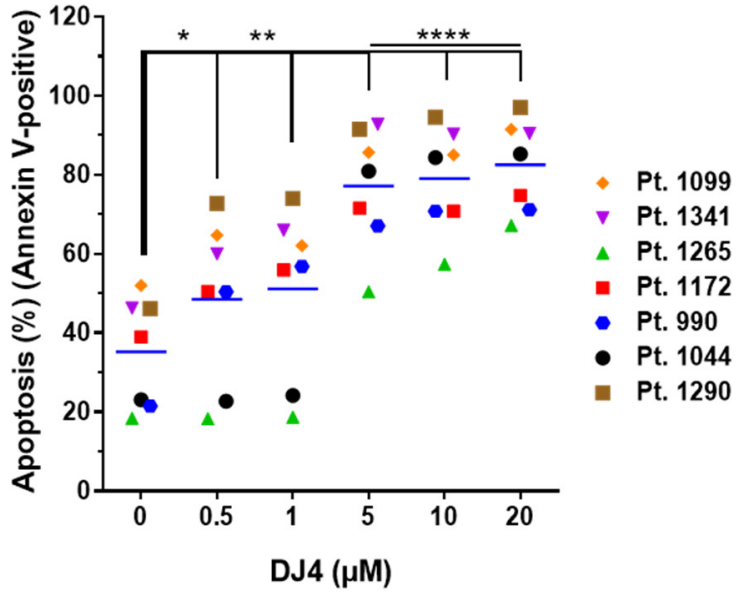

C.

DJ4
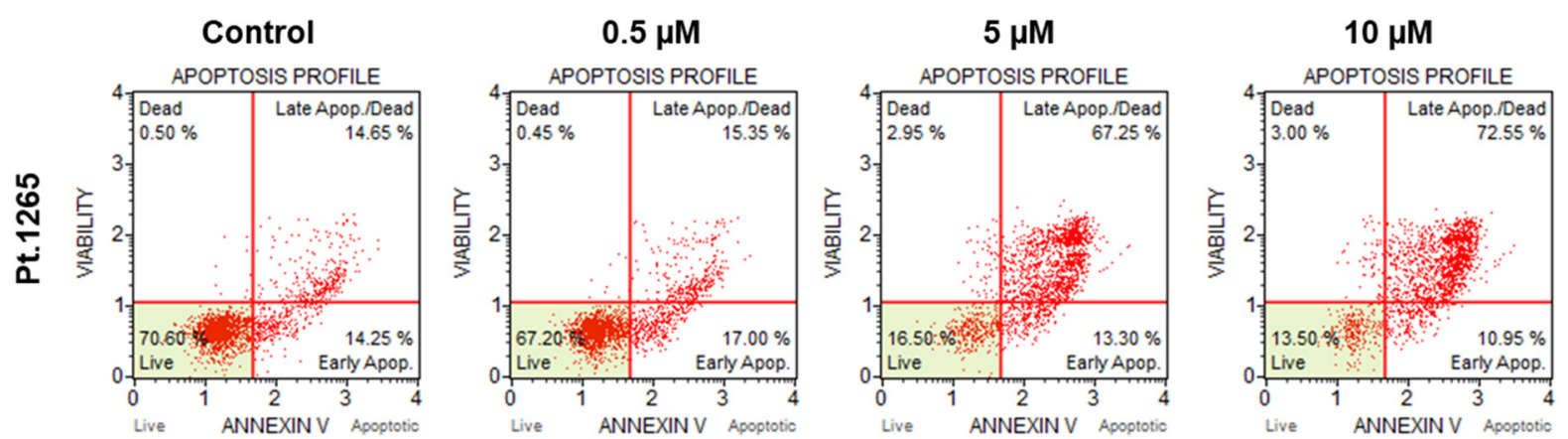

Figure 3. DJ4 treatment exerts a proapoptotic effect in AML cell lines and primary samples. (A) Induction of apoptosis was measured as a percentage of Annexin V-positive cells upon treating the human AML cell lines with increasing concentrations of DJ4 for $24 \mathrm{~h}$. The values are reported as the means \pm SEM. (B) The apoptotic effect in the AML primary patient samples was quantified as the percentage of Annexin V-positive cells after subsequent $24 \mathrm{~h}$ DJ4 treatment (see Figure S4 for the normalized plot). The data were analyzed via two-way ANOVA (Dunnett's multiple comparisons test) to compare the grand mean apoptosis, indicated by the black line, of DJ4 treatment versus the control, wherein ${ }^{*} p<0.05,{ }^{* *} p<0.01,{ }^{* * * *} p<0.0001$ were considered significant. (C) Representative flow plots of the live, dead, and apoptotic populations (early and late apoptosis) upon treating AML primary cells with DJ4 $(0-10 \mu \mathrm{M})$. The data are the result of two independent experiments.

\subsection{DJ4 Effectively Inhibits the ROCK/MYPT1/MLC2 Pathway}

The effect of DJ4 treatment on the phosphorylation of ROCK downstream targets, MYPT1 and MLC2, was assessed. The AML cell lines, MV4-11 and OCI-AML3, were treated with DJ4 in DMSO $(0-1 \mu \mathrm{M})$. The whole cell lysates were prepared after $24 \mathrm{~h}$ of drug treatment and analyzed via immunoblot analysis (Figure 4). Upon treating MV4-11 (Figure 4A) and OCI-AML3 (Figure 4B) with increasing concentrations of DJ4, the levels of phosphorylated MYPT1 and MLC2 were reduced in a dose-dependent manner relative to the loading control GAPDH (Figure 4C,D) while retaining the levels of unphosphorylated analogs of these substrates and ROCK1 and ROCK2. Additionally, lower concentrations of DJ4 were needed to significantly reduce the levels of phosphorylated MYPT1 and MLC2 in MV4-11 $(0.04-0.06 \mu \mathrm{M})$ versus OCI-AML3 $(0.6-1 \mu \mathrm{M})$. This behavior of increased sensitivity of MV4-11 to DJ4 versus OCI-AML3 is comparable to what was observed with the aforementioned cytotoxicity and apoptotic assays (Figure 1B-E and Figure 3A). This supports the in vitro studies by Kale et al. who demonstrated the potency of DJ4 to selectively inhibit ROCK1/2 and MRCK $\alpha / \beta$ in various human cancer cell lines. [50]. Similarly, DJ4 inhibited the activity of MYPT1 and reduced the levels of MLC2 [50]. 

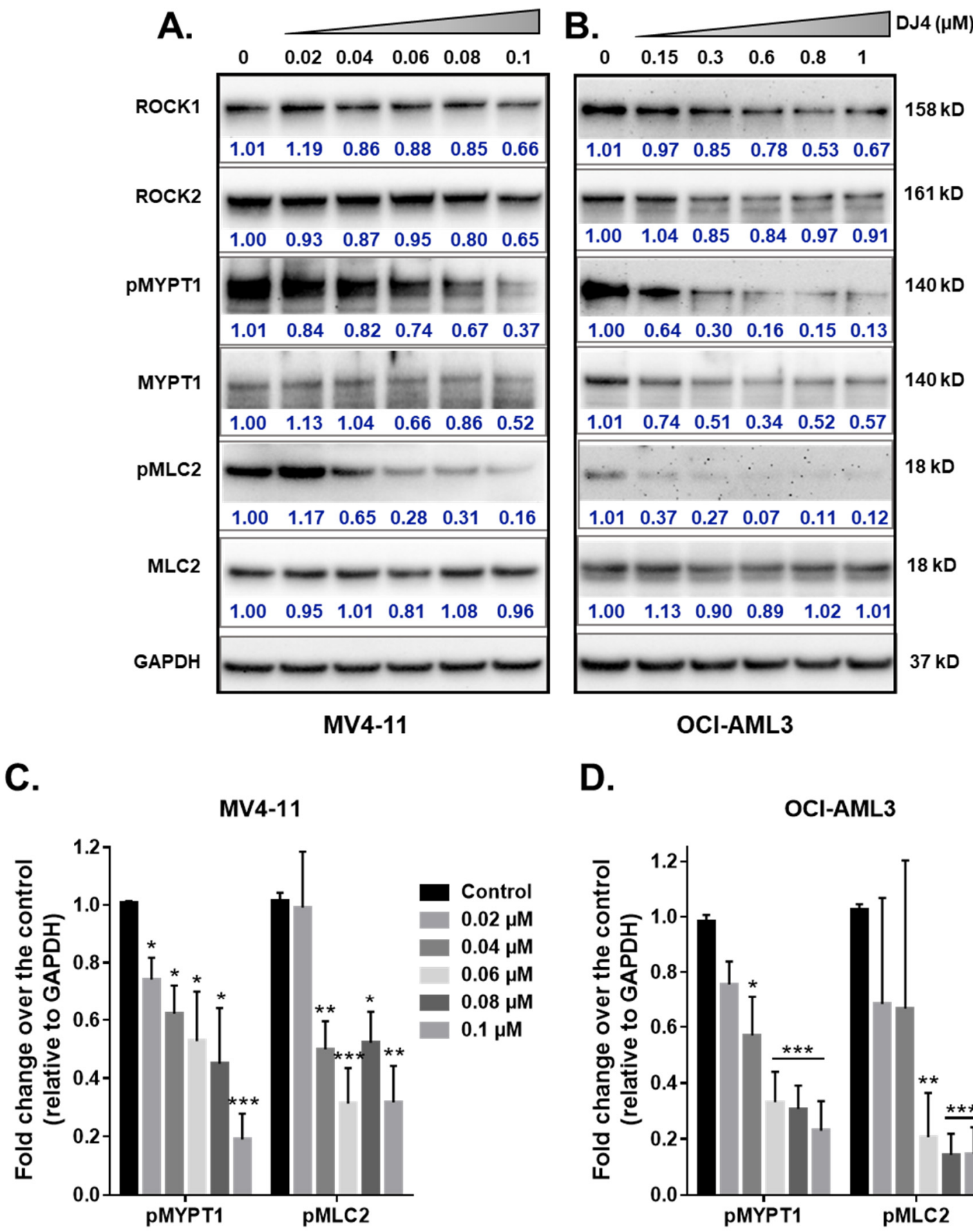

OCI-AML3

D.

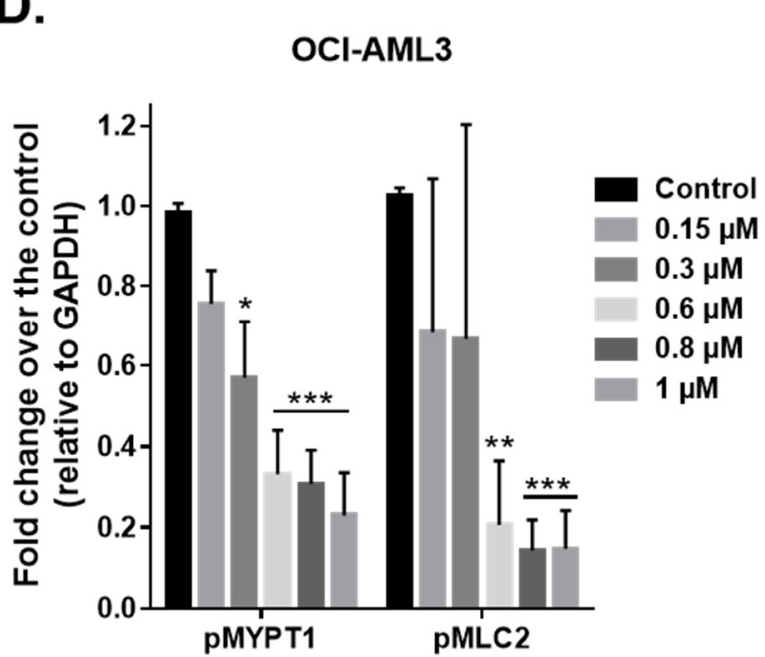

Figure 4. DJ4 effectively inhibits downstream ROCK substrates in human AML cell lines. Immunoblot analysis of the relative activity of MYPT1, MLC2, and expression levels of ROCK1, and ROCK2 upon treating the whole cell lysates of (A) MV4-11 and (B) OCI-AML3 with DJ4 for $24 \mathrm{~h}$. The phosphorylated levels of MYPT1 and MLC2 relative to the loading control GAPDH in (C) MV4-11 and (D) OCI-AML3 in the presence of DJ4 were quantified. The data were representative of three independent experiments. The results were assessed by means of the unpaired $t$-test and ${ }^{*} p<0.05,{ }^{* *} p<0.01$, and *** $p<0.005$ were considered significant. The data are the means $\pm \operatorname{SEM}(n=3)$.

\subsection{Systemic Administration of DJ4 Is Well-Tolerated by Mice without Adverse Side Effects}

DJ4 was formulated in DMSO; thus, the maximum tolerated dose (MTD) was conducted via intraperitoneal injection. The MTD was established to be $10 \mathrm{mg} / \mathrm{kg}$. The mice were then treated with the DMSO vehicle $(n=5)$ and $10 \mathrm{mg} / \mathrm{kg}$ DJ4 $(n=5)$ I.P. for 2.5 weeks, wherein the drug was administered once a day for 5 days with a 2-day break in a cycle. 
Drug treatment had a negligible impact on the body weight (less than $10 \%$ of the body weight lost), and no signs of illness were observed over time (Figure 5A, Table S2). The control and DJ4 treatment groups had comparable complete blood counts (CBC) with differential values suggesting drug treatment did not cause severe underlying conditions (Table S3). A metabolic panel to analyze renal function (CREA and BUN), liver function (ALKP, ALT, and AST) and common electrolytes in the blood collected from the control and DJ4 treatment groups was also examined (Table S4). The similar values from the chemistry panel between the groups indicate the levels of glucose, fluid, and electrolytes or the function of kidneys, liver, and other organs were not adversely affected by DJ4 (Table S4). Pharmacokinetic analysis indicated that approximately one hour after I.P. administration of DJ4 $(10 \mathrm{mg} / \mathrm{kg}) \sim 50 \%$ of the drug remained in the blood, and after three to six hours, the level of DJ4 in the blood was negligible (Figure 5B). Further, H\&E staining of the kidney, liver, lung, and spleen tissues of the mice treated I.P. for 2.5 weeks with DMSO or DJ4 indicated the cell and organ morphology was not affected by drug treatment (Figure 5C-F). Thus, the mice tolerated $10 \mathrm{mg} / \mathrm{kg}$ DJ4 via I.P. administration without any overt signs of illness and harmful effects to their system.

A.

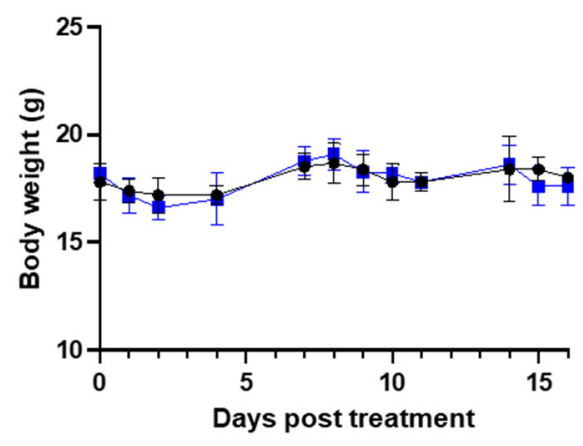

B.

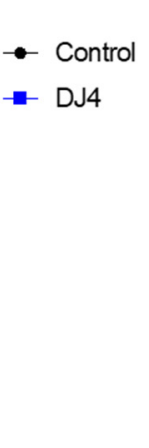

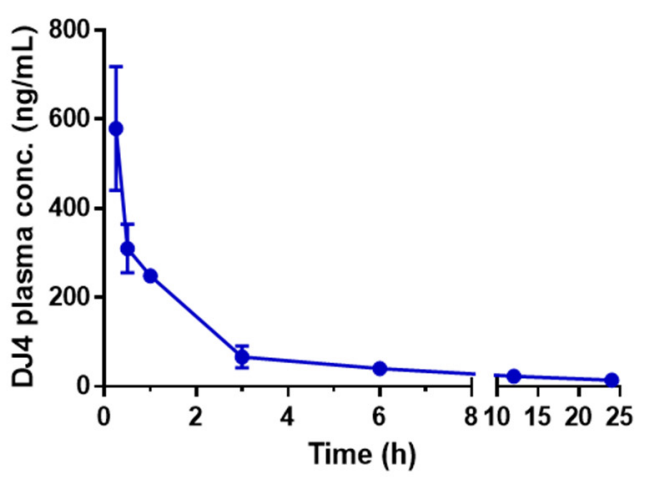

E.
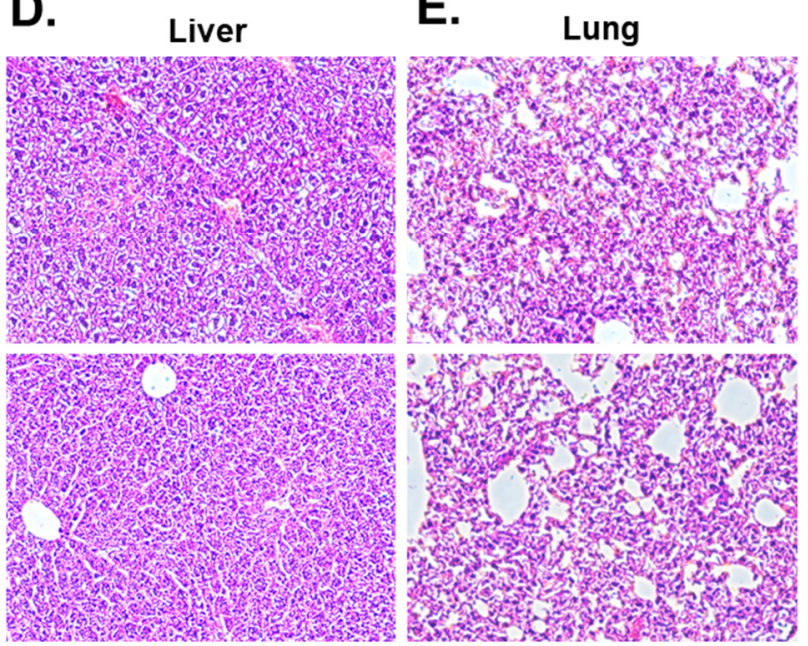

F. Spleen

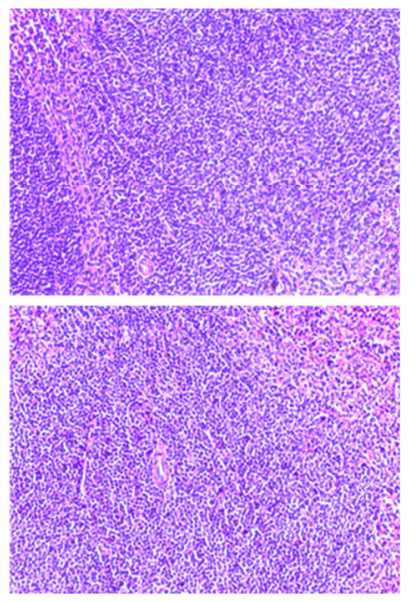

Figure 5. Intraperitoneal administration of $10 \mathrm{mg} / \mathrm{kg}$ DJ4 for 2.5 weeks was tolerated in the mice without systemic toxicity. (A) The weights ( $\mathrm{g}$ ) of the mice treated with the vehicle versus DJ4 were comparable. The values are represented as the means \pm SD ( $n=5$, see Table S2 for the average body weight values). (B) Pharmacokinetic analysis to quantify the concentration of DJ4 in the serum of the treated mice at various time points $(0.15-24 \mathrm{~h})$. The values are represented as the mean $\pm \operatorname{SEM}(n=3)$. (C-F) Cross-sections of kidney $(\mathbf{C})$, liver $(\mathbf{D})$, lung $(\mathbf{E})$, and spleen $(\mathbf{F})$ tissues from the mice treated with DMSO (top) and DJ4 (bottom) that were formalin-fixed, paraffin-embedded, and hematoxylin-and eosin-stained to examine the cell or organ morphology. Magnification: $20 \times$. 


\subsection{DJ4 Reduces Disease Progression and Enhances Survival in AML CDX Murine Models}

Efficacy of intraperitoneal DJ4 administration $(10 \mathrm{mg} / \mathrm{kg})$ in tumor-bearing mice was assessed utilizing the AML cell lines relatively sensitive to drug treatment, OCI-AML3 and MV4-11. The cell line-derived xenograft models, OCI-AML3-YFP-Luc and MV4-11-Luc2EGFP, were established utilizing flow cytometry, wherein the YFP/GFP expression was greater than 95\% relative to the unlabeled cells (Figure S5). Further, MTS cell proliferation assay showed no significant differences in DJ4 treatment response between the labeled and unlabeled AML cell lines (Figure S6). The CDX models were then optimized (e.g., cell number) in the immunocompromised NRG-S mice prior to therapeutic studies. The mice subcutaneously injected with OCI-AML3-YFP-Luc were treated with the vehicle DMSO $(n=5)$ or $10 \mathrm{mg} / \mathrm{kg}$ DJ4 $(n=5)$ for three weeks (Figure $6 \mathrm{~A})$. The bioluminescent signals or average radiance $\left(\mathrm{p} / \mathrm{s} / \mathrm{cm}^{2} / \mathrm{sr}\right)$ of the subcutaneously injected OCI-AML3-YFP-Luc mice were comparable on day seven between the control and treatment groups (Figure 6B,C), though on day thirty, a significant, at least threefold reduction in the average radiance was observed in the DJ4-treated group relative to the control group (Figure 6B,C). After day 12 , a significant difference was observed in the tumor volume between the control and treatment groups (Figure 6D). The tumor volume on day 30 was significantly, $\sim 4$-fold lower in the DJ4-treated OCI-AML3-YFP-Luc mice versus the control group (Figure 6D), and the tumor weight was significantly reduced ( 3-fold) (Figure 6E). On day 30, the average tumor volume and tumor weight of the control group were $\sim 2000 \mathrm{~mm}^{3}$ and $\sim 1700 \mathrm{mg}$ in comparison to the smaller values shown for the DJ4-treated group where average tumor volume and weight of $\sim 500 \mathrm{~mm}^{3}$ and $\sim 500 \mathrm{mg}$ were observed (Figure 6D,E). It was apparent by gross examination that the tumor sizes of the DJ4-treated mice were considerably reduced relative to the control mice among the subcutaneously injected OCI-AML3 mouse model (Figure 6E). The mice subcutaneously injected with MV4-11Luc2-EGFP followed by intraperitoneal DJ4 treatment also had tumor volumes and weights reduced $\sim 3$-fold and $\sim 2$-fold, respectively, after intraperitoneal DJ4 treatment $(n=3)$ for 3 weeks compared to the control group $(n=3)$ (Figure S7). At the end of the study, the average tumor weight and tumor volume of the control group were approximately $0.55 \mathrm{~g}$ and $1200 \mathrm{~mm}^{3}$ relative to $0.25 \mathrm{~g}$ and $400 \mathrm{~mm}^{3}$ of the DJ4-treated group (Figure S7). Additionally, the OCI-AML3-YFP-Luc CDX was administered intravenously, and the effect of DJ4 intraperitoneal treatment was assessed (Figure 6F). There was a moderate benefit reducing the average bioluminescent signal (Figure $6 \mathrm{G}, \mathrm{H}$ ) and increasing the overall survival (Figure 6I) in the DJ4-treated group versus the control group. DJ4-treated mice exhibited a twofold decrease in the bioluminescent signal on day 36 (Figure $6 \mathrm{H}$ ) and lived 5 days longer than the control group (Figure 6I). 
A. OCI-AML3-YFP-LUC

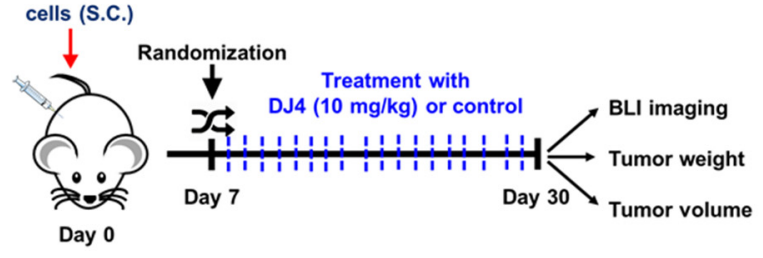

B.

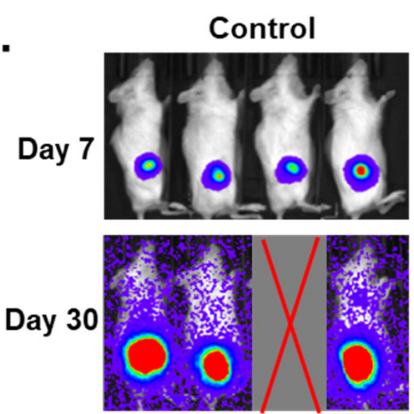

D.

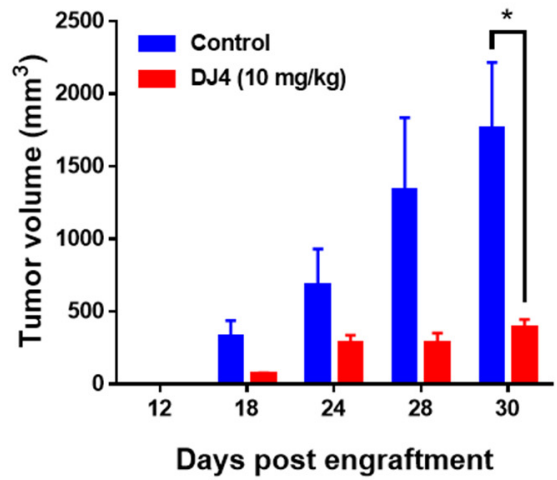

F.

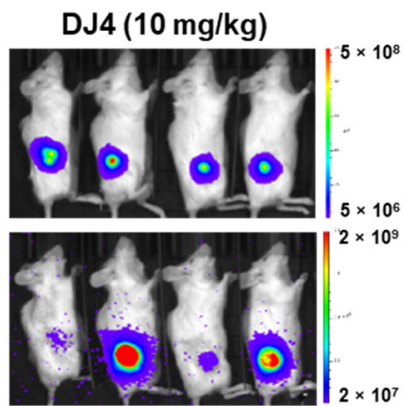

E.

G. c.

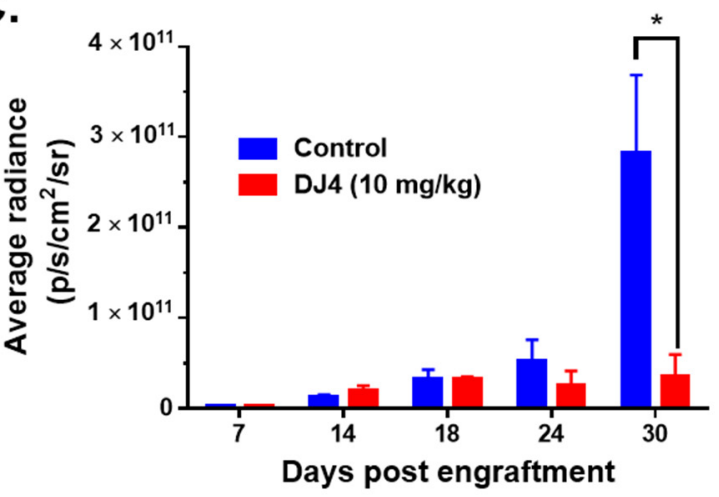

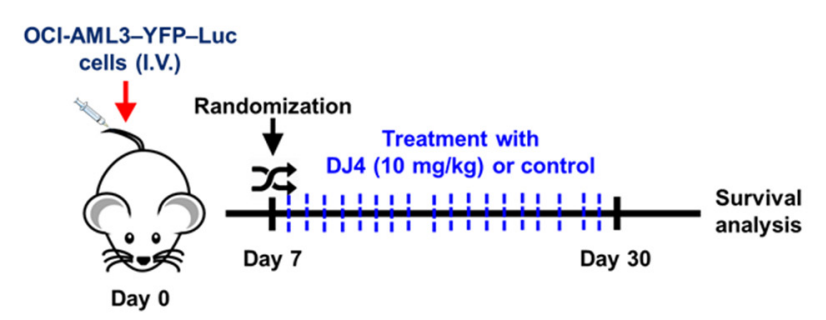

H.

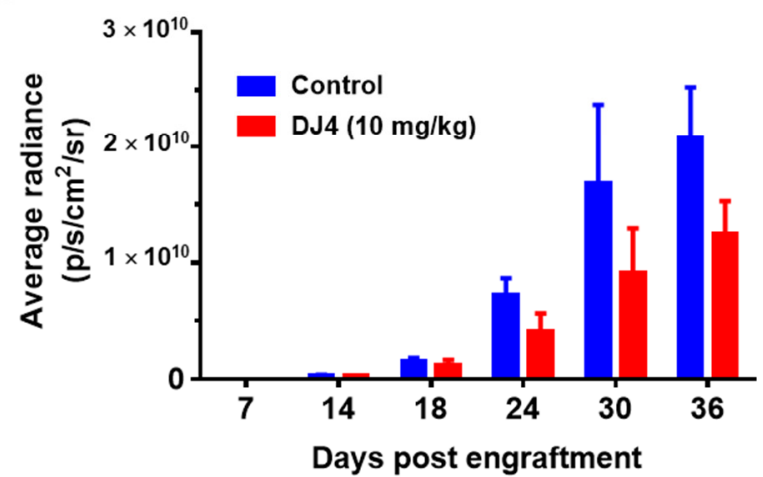

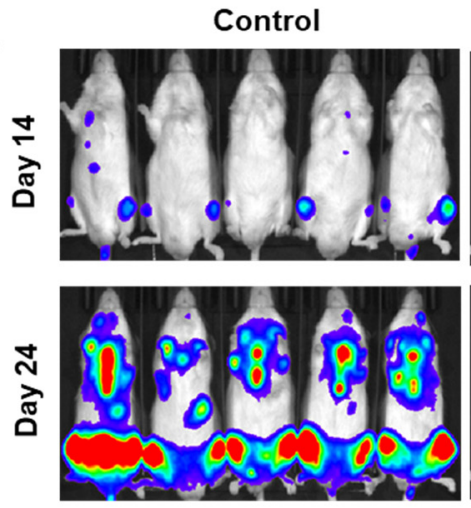

DJ4 (10 mg/kg)

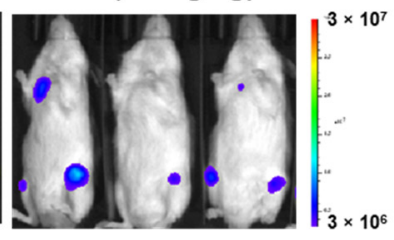

I.

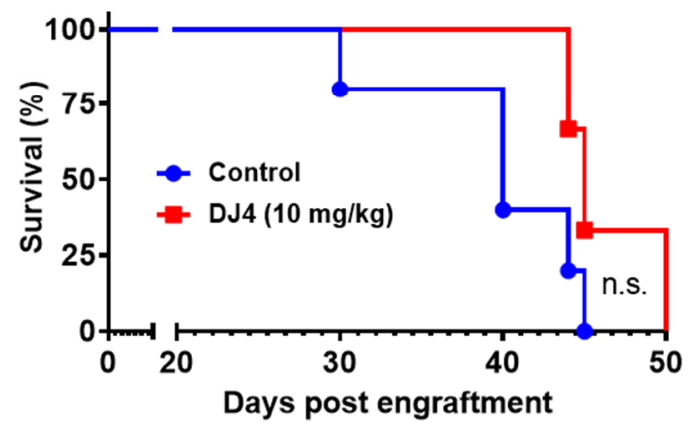

Figure 6. DJ4 administration $(10 \mathrm{mg} / \mathrm{kg})$ for three weeks was efficacious in the disseminated and subcutaneous models of OCI-AML3-YFP-Luc-injected mice. (A) The labeled OCI-AML3 cells were administered subcutaneously to the immunocompromised NRG-S mice and segregated into treatment groups based on their bioluminescent signal on day seven. 
The mice were subdivided in a manner to ensure the average signal between both groups was comparable at the start of the study and then treated with either the vehicle or DJ4. The average radiance $\left(\mathrm{p} / \mathrm{s} / \mathrm{cm}^{2} / \mathrm{sr}\right)$, tumor volume $\left(\mathrm{mm}^{3}\right)$, and tumor weights $(\mathrm{mg})$ of the animals were measured over time. The results were assessed by means of the unpaired $t$-test, wherein * $p<0.05$ was considered statistically significant. (B) Images of the subcutaneous tumor of the control and DJ4-treated mice on days 7 and 30. (C) Bioluminescent signal of the DJ4-treated mice relative to the control group over time. (D) Volumes of the subcutaneous tumors in the mice that were administered DJ4 as compared to the vehicle-treated mice over the course of the study. (E) The tumor weights of the DJ4-treated mice and the gross examination of the tumor sizes in the groups. (F) The immunocompromised NRG-S mice were intravenously injected with the OCI-AML3-YFP-Luc cells. The mice were randomized into the vehicle- or DJ4-treated group based on their bioluminescent signal on day seven to ensure the average intensity was similar in both groups at the start of the study. The mice were intraperitoneally treated with the vehicle or DJ4 for 3 weeks and the survival advantage of drug treatment was monitored. IVIS imaging of the mice took place every few days. (G) Images of the DJ4-treated mice relative to the control group on days 14 and 24. (H) Bioluminescent signal measured as the average radiance of the DJ4-treated mice versus the control group as observed over time. The values were examined by means of the $t$-test, and ${ }^{*} p<0.05$ was considered statistically significant. (I) Kaplan-Meier survival analysis of the DJ4 group versus the vehicle-treated group. The results were assessed by means of the Gehan-Breslow-Wilcoxon test. The data are the means \pm SEM; n.s. denotes not significant.

\subsection{DJ4-Pretreated AML CDX Models Lead to Reduced Leukemia Burden and Prolonged Survival in Mice}

The luciferase-expressing modified cell lines were also pretreated with DJ4 in vitro for $24 \mathrm{~h}$ and subsequently injected intravenously into the NRG-S mice and monitored without further treatment (Figure 7A). The bioluminescent signal was significantly reduced in the mice that received the DJ4-treated cells $(n=4-5)$ versus those that received the DMSO vehicle-treated cells $(n=4-5)$ (Figure $7 \mathrm{~B}, \mathrm{C}, \mathrm{E}, \mathrm{F})$, and the overall survival was greater by 10 to 20 days in the drug treatment group (Figure 7D,G). The mice injected with the DJ4-treated OCI-AML3-YFP-Luc and MV4-11-Luc2-EGFP cells experienced an $\sim 3$-fold decrease on day 25 and a $\sim 4$-fold reduction on day 38 in bioluminescent intensity, respectively (Figure 7B,C,E,F). Bone marrow and spleen tissues isolated from the control and treatment groups of the disseminated murine studies were analyzed by means of flow cytometry (Figure S8). Flow cytometry analysis indicated a significant reduction in the percentage of hCD45-positive cells in the spleen of the DJ4-pretreated MV4-11 mice by $\sim 1.2$-fold relative to the control group (Figure S8A) and a decrease in the hCD45 population by $\sim 2.5$-fold versus the control group in the bone marrow of the DJ4-pretreated OCI-AML3-injected mice (Figure S8B). 
A.

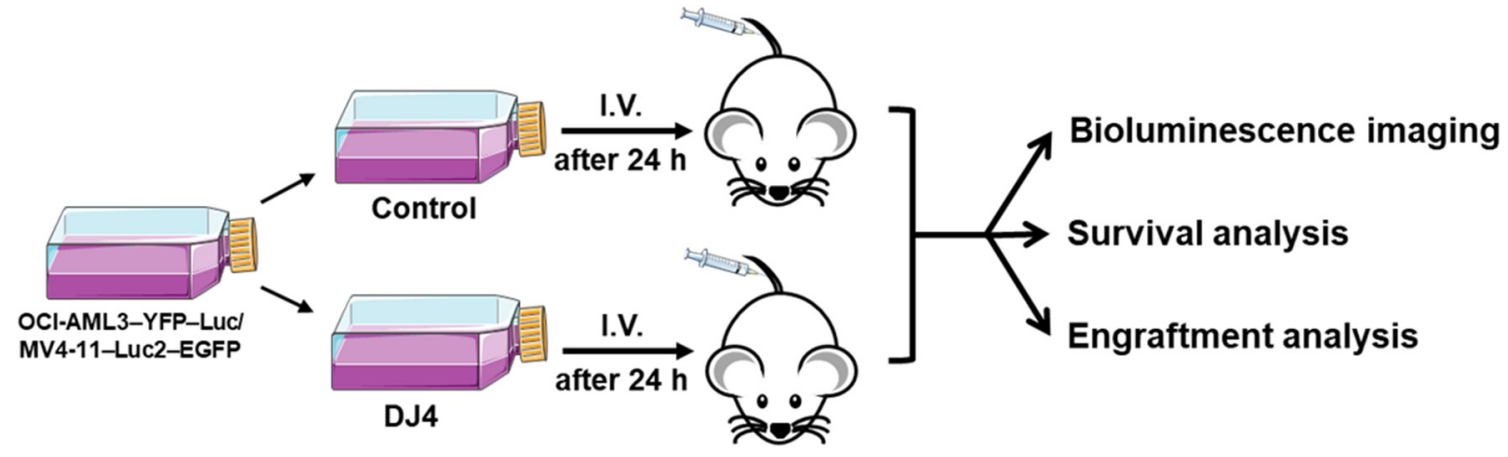

B.

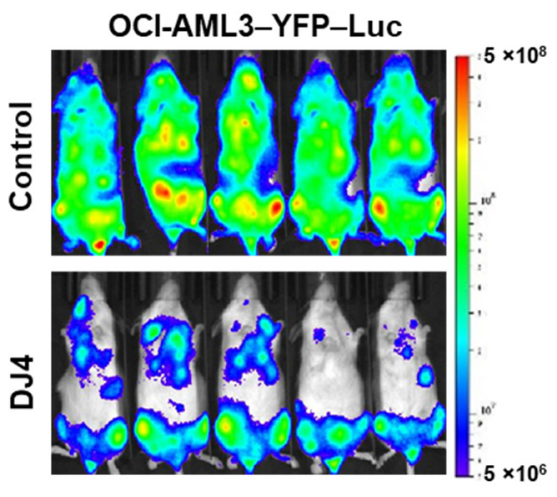

E.

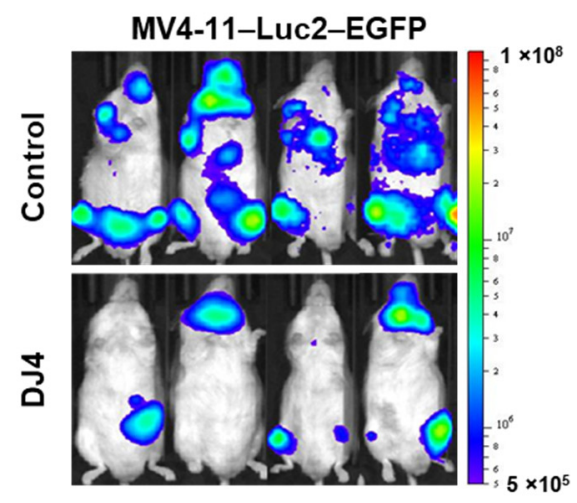

C.

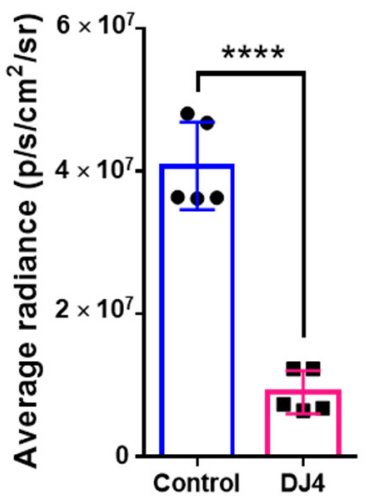

F.

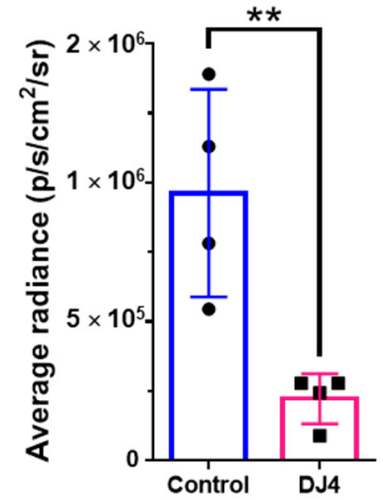

D.

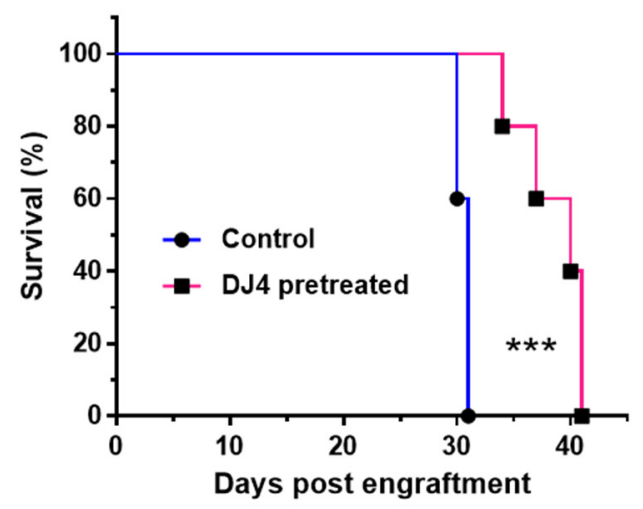

G.

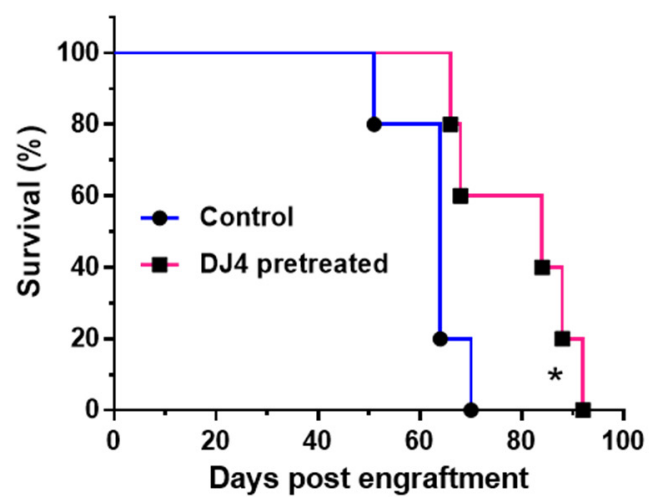

Figure 7. Disease progression and survival analysis of the mice that were intravenously injected with the AML cell lines that were pretreated with DJ4 for $24 \mathrm{~h}$. (A) The modified AML cell lines, OCI-AML3-YFP-Luc and MV4-11-Luc2-EGFP, were treated with their respective $\mathrm{IC}_{50}$ dose of DJ4 (Figure $1 \mathrm{~B}, \mathrm{C}$ ) or with the vehicle for $24 \mathrm{~h}$. The treated cells were then intravenously administered to the NRG-S mice, and the survival advantage was monitored over time without further treatment. The mice were imaged every few days to visualize and quantify disease progression. Flow cytometry analysis on the bone marrow and spleen tissues of the vehicle- and DJ4-treated mice was also performed to track disease progression by measuring the percentage of engraftment of the human cancer cells (see Figure S8). (B) Imaging on day 25 of the DJ4-pretreated OCI-AML3-YFP-Luc-injected mice versus the control group. (C) Bioluminescence imaging measured by the average radiance $\left(\mathrm{p} / \mathrm{s} / \mathrm{cm}^{2} / \mathrm{sr}\right)$ on day 25 of the DJ4-pretreated OCI-AML3-YFP-Luc-injected group versus the control mice. (D) Survival observed among the mice that received the OCI-AML3 cells that were pretreated with DJ4 versus DMSO. (E) Imaging on day 38 of the MV4-11-Luc2-EGFP-injected mice that were pretreated with DJ4 versus DMSO. (F) The average radiance observed on day 38 in the MV4-11 cells that were pretreated with DJ4 as compared to the DMSO-pretreated mice. (G). Kaplan-Meier survival analysis of the DJ4-pretreated MV4-11-injected mice relative to the DMSO-pretreated MV4-11-injected mice. The data are the means \pm SD. The values in $(\mathbf{C}, \mathbf{F})$ were assessed by means of the unpaired $t$-test, with ${ }^{* *} p<0.01$ and ${ }^{* * * *} p<0.0001$ considered statistically significant. The results in $(\mathbf{D}, \mathbf{G})$ were examined by means of the Gehan-Breslow-Wilcoxon test, wherein ${ }^{*} p<0.05$ and ${ }^{* * *} p<0.005$ were considered statistically significant. 


\section{Discussion}

Patients diagnosed with acute myeloid leukemia exhibit a multitude of genetically diverse molecular alternations or abnormalities [55]. This leads to many different subsets of this disease and complicates treating patients in a generic way. Simplifying the vast molecular landscape of AML to find a suitable therapeutic target requires extensive epigenetic and in vivo investigations. The recent studies have aimed to identify recurrent mutations and establish trends in treatment response among patient samples with targeted inhibitors. This can aid in drug development, determining relationships across multiple signaling pathways, and identifying coinciding abnormalities. Mutation-specific targeted therapeutics such as midostaurin, enasidenib, or ivosidenib toward common AML mutations such as FLT3, IDH1, or IDH2 may help improve current therapy for subgroups manifesting these mutations [56-58]. For many older patients, the recent addition of venetoclax, a BLC2targeting agent, shows improving outcomes. These improvements are, however, transient for most patients, as the majority currently relapse and succumb to the resistant disease.

Expression and mutation profiling studies suggest cancer therapy designed to modulate ROCK activity may improve the prognosis of AML patients. Upregulation of mRNA expression of ROCK1 was observed in thirty-nine AML cell lines from the Cancer Cell Line Encyclopedia (CCLE) database (Figure S1). The Cancer Genome Atlas (TCGA) database of the NIH also indicated ROCK1 overexpression affects the survival of AML patients and correlates well with poor prognosis and survival in AML patients (Figure S2). Loss-of-function RNA interference (RNAi) experiments in AML patient samples identified the knockdown of ROCK1 to reduce the growth and viability of leukemic progenitor cells [59]. Additionally, overexpression of ROCK has been shown to regulate migration and invasion in various cancers $[28,60,61]$. Potential targeting of the ROCK pathway could modulate cellular proliferation, cell shape and motility, tumor progression and metastasis for therapeutic benefit $[41,61]$. Mali et al. showed that mutated tyrosine kinase receptors of cells expressing oncogenic forms of KIT, FLT3, and Bcr-Abl constitutively activate the serine/threonine kinase, ROCK [44,62]. Accordingly, AML cell lines (MV4-11 and MOLM-13) and primary AML patient cells which carry the FLT3-ITD or KIT mutation exhibited sensitivity to ROCK inhibitor DJ4 (Figures 1 and 2). Inhibition of the downstream effector of Rho GTPases, ROCK1, by fasudil, H-1152 (dimethylfasudil), or Y27632 resulted in antiproliferative effects on cancer cells suggesting its promise as an AML treatment $[44,62,63]$. ROCK inhibitors such as fasudil have been established to be safe for administration in humans, but for treatment of other diseases such as cerebral vasospasm, thereby highlighting their clinical tolerability $[61,64]$. Moreover, the role of the Rho-ROCK pathway as a therapeutic target has been established for various vascular disorders [61,65]. ROCK inhibition may promote normalized tumor vasculature allowing for greater efficacy of chemotherapeutics [61,65], suggesting its potential to work synergistically with the current AML therapeutics. Multiple ROCK inhibitors are needed such as fasudil and presently DJ4 because they may be suitable for certain subsets of AML or more effective in combination with different cancer therapy regimens. Combined inhibition of ROCK and MRCK was previously shown to be more potent in inhibiting actomyosin-regulated functions [41,48,49]. DJ4's activity to target multiple kinases with similar functions relating to cancer cell migration/invasion [50] builds on the literature relating to the development and design of novel ROCK inhibitors and may even work synergistically with other ROCK inhibitors resulting in a more potent treatment. Future studies will examine DJ4 in combination with other ROCK inhibitors or standard-of-care AML treatments to provide further support for their clinical use in cancer.

Activation of ROCK by Rho results in the phosphorylation of MYPT1, reduced myosin phosphatase activity, and enhanced phosphorylation of the regulatory myosin light-chain 2 substrate $[61,66]$. Mali et al. demonstrated that PI3K and Rho GTPase regulated activation of the Rho-ROCK pathway results in various leukemic transformations. Stimulation of ROCK1 phosphorylates downstream MLC2 on Ser119, corresponding to actin and myosin changes that promote the acceleration of leukemia cell proliferation; this has been suggested to have consequences for myeloproliferative neoplasms (MPNs) and AML [44,62]. Further, 
investigations inhibiting ROCK resulted in the diminished proliferation of leukemic cells with activated KIT signaling $[44,62,63]$. In line with the available literature, immunoblotting analysis of downstream targets of ROCK, MYPT1 and MLC2, upon treating with DJ4 resulted in reduced levels of the phosphorylated substrates as observed in Figure 4 . This provides further support of Kale et al.'s observations [50] that DJ4 effectively inhibits ROCK functionality and that the in vivo efficacy observed in this report is in part due to the inhibition of the ROCK/MYPT1/MLC2 axis. The ROCK/MYPT1/MLC2 pathway aids in the regulation of stress fiber assembly, cell adhesion, and motility [61,66]. Inhibition of this pathway has shown suppressed cellular proliferation, invasion, and angiogenesis via in vitro analysis and diminished tumor growth and metastasis formation through in vivo studies, which has been demonstrated in previous works [44,59,61,67-73].

DJ4 induced potent cytotoxic effects in the AML cell lines with various mutations. DJ4 treatment was also active versus various AML patient-derived cells harboring mutations such as U2AF1, FLT3-ITD, HOXA9/NUP98, NPM1, KIT, and CBL (Figures 1 and 2, Table 1 and Table S1). The cell lines and AML patient cells carry mutations in different oncogenes and signaling pathway genes (Figure $1 \mathrm{C}$ and Table 1 ). AML patient samples are highly heterogenous, with an abundance of mutations, and thus the AML cell lines tended to be more sensitive to DJ4 treatment than the AML patient samples. The observed potency of DJ4 towards various AML cell lines and primary samples with a diverse set of mutations suggests that this is a promising candidate to be incorporated into the standard AML regimen to help many different subsets of AML patients.

In aggressive cases of this disease, the timing to determine the appropriate targeted treatment regimen for a patient can be a limiting factor, therefore finding a targeted therapy that can impart some efficacy and slow disease progression to a wide range of patient groups can be advantageous. The observed diminished leukemic cell proliferation was in part due to the proapoptotic effect induced by DJ4 (Figure 3 and Figures S3 and S4). Therapeutics that induce apoptosis have been shown to be promising candidates toward overcoming chemoresistance and reducing disease progression and work well with appropriate combinations of the standard-of-care drugs [55,74,75]. Interestingly, DJ4 was less active in inhibiting colony formation among normal hematopoietic cells and exhibited only modest hematopoietic toxicity in mice. Therefore, a favorable therapeutic index is postulated, with much greater inhibition of many leukemias than of normal myelopoiesis.

The moderately DJ4-sensitive AML cell line OCI-AML3 and the more sensitive AML cell line MV4-11 (as demonstrated by in vitro assays) were selected to examine the efficacy of DJ4 in murine studies. OCI-AML3 [59] and MV4-11 [44] are also common AML cell lines utilized to examine the efficacy of ROCK inhibitors and, thus, to be consistent with the literature, they were utilized in this report. The mice that were intravenously or subcutaneously injected with OCI-AML3-YFP-Luc or MV4-11-Luc2-EGFP were intraperitoneally treated with DJ4 for three weeks (Figure 6A,F). The reduction of the bioluminescent signal or decreased size of the tumor in volume and weight observed with the cell-derived xenograft models indicated that DJ4 effectively slowed the progression of AML (Figure 6 and Figure S7). This was further demonstrated by the fact that DJ4 treatment resulted in greater overall survival. Efficacy observed after administration of DJ4 to both the disseminated and subcutaneous models suggests the promise of this drug towards different tumor microenvironments. The mice that were intravenously administered DJ4pretreated AML cells also exhibited a decreased bioluminescent signal, increased survival of 10 and 20 days, and a reduction in the percentage of human CD45 cells in the bone marrow or spleen, indicating a diminished tumor burden (Figure 7 and Figure S8). Treatment of AML mouse models with DJ4 resulted in a significant inhibition of leukemia growth (Figures 6 and 7) without systemic toxicity (Figure 5 and Tables S2-S4). It was unexpected that DJ4 would result in the observed in vivo efficacy due to its poor pharmacokinetics; however, this may be due to the prolonged presence of DJ4 in various tissues such as the liver and tumors. The development of better formulations or variants of DJ4 to improve the pharmacokinetic profile of this treatment may enhance efficacy. Future studies will be 
focused on gaining insights into the impact of DJ4 on the molecular level to understand in its entirety which signaling pathways or proteins are affected.

ROCK has been shown to regulate proliferation of ITD-FLT3 hematopoietic cells $[44,76]$. ITD-FLT3 mutations in human AML stem cells are present in 20-30\% of AML patients and have been implicated in the poor prognosis and refractory phenotype of this disease [77-82]. Onish et al. reported that ITD-FLT3 mutations enhance the leukemic cell migration toward the chemokine Cxcl12 by inhibiting the downregulation of ROCK1 and dephosphorylation of MYPT1 $[76,83]$. This can result in the hematopoietic stem cells being retained in the bone marrow and protected from AML therapy $[76,84,85]$. It may be suggested that the improved condition of the MV4-11 mice with DJ4 (Figure 7E,G and Figures S7 and S8) is a result of the decreased ROCK functionality which may be regulating the ITD-FLT3 activity to reduce Cxcl12-induced leukemic cell migration. The decreased AML chemotaxis to this therapy-protective bone marrow microenvironment can allow for the release of leukemia cells and lead to the considerable therapeutic efficacy observed with DJ4 in murine studies. Similarly, disruption of the interaction between the leukemic cells and Cxcl12 by treating FLT3-mutated leukemic cells with the Cxcr4 inhibitor, AMD3465, resulted in the increased proapoptotic activity of an FLT3 inhibitor $[76,86]$. The scope of this report was to establish the in vivo efficacy of DJ4 and demonstrate the potential of targeting the ROCK/MYPT1/MLC2 pathway in AML. Future investigations will be held to examine signaling networks that may interact with the ROCK signaling pathway in the presence of DJ4. These studies will assess which subsets of AML are most appropriate to incorporate DJ4 into their treatment and can help identify coexisting mutations that DJ4 is also potent towards.

\section{Conclusions}

In this report, the in vivo efficacy of the selective ATP inhibitor of ROCK and MRCK, DJ4, was assessed towards AML. DJ4 was observed to downregulate ROCK functionality via the ROCK/MYPT1/MLC2 pathway (Figure 8) and result in cell death of AML cells, that is in part attributed to inducing apoptosis. AML cell lines and primary AML patient cells with various mutations were considerably sensitive to DJ4 treatment, suggesting its promise to help patients with different subsets of AML. Preclinical therapeutic murine studies showed DJ4 administration reduced leukemia progression and prolonged survival in subcutaneous or disseminated AML mouse models, without limited systemic toxicity. Future experiments will be conducted to establish trends in the treatment response to DJ4 among a larger set of AML patient cases with different cytogenetic backgrounds. This will aid in the determination of which subsets of AML would benefit most from DJ4 treatment. Efforts will be made to continue investigating the effect of DJ4 on ROCK-centered signals and understand its influence on other signaling pathways that may also be contributing to its efficacy. Overall, this study demonstrated the potential of ROCK-targeted therapy to treat patients diagnosed with AML. It also highlighted the need to develop less toxic and more effective chemotherapeutics to overcome the poor prognosis and chemoresistance that is frequently associated with AML patients. 


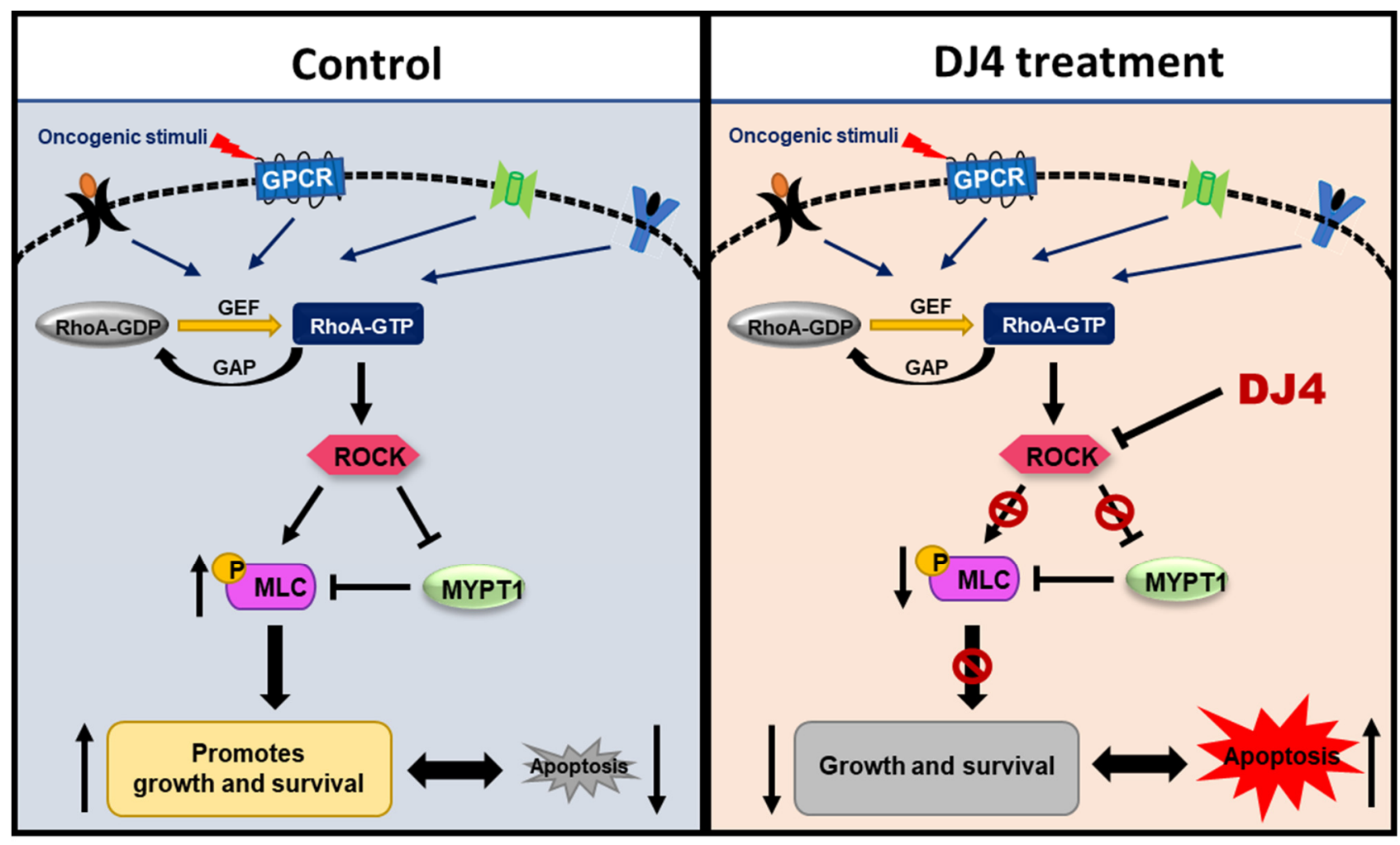

Figure 8. ROCK inhibitors such as DJ4 may reduce the phosphorylation of downstream targets such as MLC2 and MYPT1. Blocking ROCK-related pathways can potentially have therapeutic benefits by restoring proliferation and apoptotic cascades that may be improperly signaling due to malignant transformations arising from cancer.

Supplementary Materials: The following are available online at https:/ / www.mdpi.com/article/10 .3390 / cancers13194889/s1, Figure S1: ROCK 1 kinase A. and ROCK 2 kinase B. were found to be highly expressed in different cancer cell lines including among 39 AML cell lines from CCLE database, Figure S2: Survival plots of AML patients with low and high expression of ROCK 1 kinase and ROCK 2 kinase accessed from the BloodSpot database, Figure S3: Cell cycle analysis was performed on human AML cell lines in the presence of increasing concentrations of DJ4 for $24 \mathrm{~h}$, Figure S4: The percent of apoptosis was measured as the percent of Annexin V-positive cells upon treating AML primary samples with DJ4, Figure S5. The percent of YFP or GFP expression quantified in labeled cell lines versus their respective unlabeled control cells by flow cytometry, Figure S6: Cell proliferation quantified by MTS assay upon treating labeled cell lines and their respective unlabeled cell lines with DJ4, Figure S7: Efficacy was imparted by intraperitoneal DJ4 administration $(10 \mathrm{mg} / \mathrm{kg})$ for three weeks on the subcutaneously injected MV4-11-Luc2-EGFP model, Figure S8: Flow cytometry analysis was performed on the bone marrow and spleen tissues harvested from the modified cell lines that were pretreated with DJ4 or DMSO, Figure S9: All the whole western blot figures, Table S1: Various human AML cell lines were treated with DJ4 and the IC50 $(\mu \mathrm{M})$ values were determined by the MTS assay, Table S2: Mice were interperitoneally administered DMSO $(n=5)$ or $10 \mathrm{mg} / \mathrm{kg}$ DJ4 $(n=5)$ for 2.5 weeks and the weights of the mice were recorded over time, Table S3: Complete blood count (CBC) values, and Table S4: Clinical Chemistry values.

Author Contributions: A.S. conceptualized the project, acquired funding, supervised the studies, wrote, reviewed, and edited the manuscript. M.A.E. wrote the first draft. U.G. and M.A.E. performed experiments, analyzed the results, and edited the manuscript; U.G. and M.A.E. contributed equally. C.A., Z.Z. and D.B.T. performed experiments, analyzed the results, assisted in manuscript review, and edited the manuscript. A.T. performed experiments. A.B. performed statistical analysis. A.S. and D.C. provided the primary AML samples, and D.D. provided DJ4. T.P.L.J., M.K., D.D., A.A.D., I.E., S.A., S.D. and D.C. assisted in manuscript review and editing. All authors have read and agreed to the published version of the manuscript. 
Funding: This study was funded by the Kenneth F Noel Memorial Fund (D.F.C.), Delbert J. McQuaide Cancer Research Fund (A.S.), Austin R. Orwan Memorial Research Fund (A.S.), The Penn State Cancer Institute (PSCI), and the National Institutes of Health (NIH) under the National Cancer Institute (P01CA171983 (T.L. and M.K.) and R01CA213912 (S.D.)). Additionally, the study was funded by the Four Diamonds-supported PDX and the Therapeutic Core.

Institutional Review Board Statement: Patient samples were used in compliance with the Institutional Review Board regulations.

Informed Consent Statement: Not applicable.

Data Availability Statement: The datasets analyzed during the current study are available from the corresponding author upon request or using the link provided in the Supplementary Materials.

Acknowledgments: The authors thank those who generously provided cell lines for our studies: Barbara Miller, Penn State Hershey (U937); Xiaorong Gu, Cleveland Clinic (OCI-AML2 and OCIAML3); and H.G. Wang, Penn State Hershey (MOLM-13). The labeled cell lines were provided by Su-Fern Tan and Thomas P. Loughran Jr. from University of Virginia Cancer Center. The authors thank the staff of the Department of Comparative Medicine, Organic Synthesis Core, Mass Spectrometry and Proteomics Core, Bioluminescence Imaging Core, Flow Cytometry Core, and Four Diamonds Developmental Therapeutic Preclinical Core facilities at the Penn State University College of Medicine.

Conflicts of Interest: M.K. is the chief medical officer and cofounder of Keystone Nano, Inc. T.P.L.J. is on the scientific advisory board and has stock options of both Keystone Nano, Inc., and Bioniz Therapeutics.

\section{References}

1. Green, S.D.; Konig, H. Treatment of Acute Myeloid Leukemia in the Era of Genomics-Achievements and Persisting Challenges. Front. Genet. 2020, 11, 480. [CrossRef]

2. Naur, T.M.H.; Jakobsen, L.H.; Roug, A.S.; El-Galaly, T.C.; Marcher, C.W.; Nørgaard, J.M.; Theilgaard-Mönch, K.; Møller, P.; Schöllkopf, C.; Severinsen, M.T. Treatment intensity and survival trends among real-world elderly AML patients diagnosed in the period 2001-2016: A Danish nationwide cohort study. Leuk. Lymphoma 2021, 62, 2014-2017. [CrossRef]

3. Dohner, H.; Weisdorf, D.J.; Bloomfield, C.D. Acute Myeloid Leukemia. N. Engl. J. Med. 2015, 373, 1136-1152. [CrossRef] [PubMed]

4. Watts, J.; Nimer, S. Recent advances in the understanding and treatment of acute myeloid leukemia [version 1; peer review: 3 approved]. F1000Research 2018, 7, 1-14. [CrossRef] [PubMed]

5. Aldoss, I.; Pullarkat, V.; Stein, A.S. Venetoclax-containing regimens in acute myeloid leukemia. Ther. Adv. Hematol. 2021, 12, 2040620720986646. [CrossRef]

6. Samra, B.; Konopleva, M.; Isidori, A.; Daver, N.; DiNardo, C. Venetoclax-Based Combinations in Acute Myeloid Leukemia: Current Evidence and Future Directions. Front. Oncol. 2020, 10, 562558. [CrossRef] [PubMed]

7. Stone, R.M.; Mandrekar, S.J.; Sanford, B.L.; Laumann, K.; Geyer, S.; Bloomfield, C.D.; Thiede, C.; Prior, T.W.; Döhner, K.; Marcucci, G.; et al. Midostaurin plus Chemotherapy for Acute Myeloid Leukemia with a FLT3 Mutation. N. Engl. J. Med. 2017, 377, 454-464. [CrossRef] [PubMed]

8. Randhawa, J.K.; Kantarjian, H.M.; Borthakur, G.; Thompson, P.A.; Konopleva, M.; Daver, N.; Pemmaraju, N.; Jabbour, E.; Kadia, T.M.; Estrov, Z.; et al. Results of a Phase II Study of Crenolanib in Relapsed/Refractory Acute Myeloid Leukemia Patients (Pts) with Activating FLT3 Mutations. Blood 2014, 124, 389. [CrossRef]

9. Uy, G.L.; Mandrekar, S.J.; Laumann, K.; Marcucci, G.; Zhao, W.; Levis, M.J.; Klepin, H.D.; Baer, M.R.; Powell, B.L.; Westervelt, P.; et al. A phase 2 study incorporating sorafenib into the chemotherapy for older adults with FLT3-mutated acute myeloid leukemia: CALGB 11001. Blood Adv. 2017, 1, 331-340. [CrossRef]

10. Nagata, H.; Worobec, A.S.; Oh, C.K.; Chowdhury, B.A.; Tannenbaum, S.; Suzuki, Y.; Metcalfe, D.D. Identification of a point mutation in the catalytic domain of the protooncogene c-kit in peripheral blood mononuclear cells of patients who have mastocytosis with an associated hematologic disorder. Proc. Natl. Acad. Sci. USA 1995, 92, 10560-10564. [CrossRef]

11. Hirota, S.; Isozaki, K.; Moriyama, Y.; Hashimoto, K.; Nishida, T.; Ishiguro, S.; Kawano, K.; Hanada, M.; Kurata, A.; Takeda, M.; et al. Gain-of-function mutations of c-kit in human gastrointestinal stromal tumors. Science 1998, 279, 577-580. [CrossRef] [PubMed]

12. Shtivelman, E.; Lifshitz, B.; Gale, R.P.; Canaani, E. Fused transcript of abl and bcr genes in chronic myelogenous leukaemia. Nature 1985, 315, 550-554. [CrossRef] [PubMed]

13. Cortes, J.; Kantarjian, H.; Ball, E.D.; Dipersio, J.; Kolitz, J.E.; Fernandez, H.F.; Goodman, M.; Borthakur, G.; Baer, M.R.; Wetzler, M. Phase 2 randomized study of p53 antisense oligonucleotide (cenersen) plus idarubicin with or without cytarabine in refractory and relapsed acute myeloid leukemia. Cancer 2012, 118, 418-427. [CrossRef] [PubMed] 
14. Lehmann, S.; Bykov, V.J.; Ali, D.; Andren, O.; Cherif, H.; Tidefelt, U.; Uggla, B.; Yachnin, J.; Juliusson, G.; Moshfegh, A.; et al. Targeting p53 in vivo: A first-in-human study with p53-targeting compound APR-246 in refractory hematologic malignancies and prostate cancer. J. Clin. Oncol. 2012, 30, 3633-3639. [CrossRef]

15. Stein, E.M.; DiNardo, C.D.; Pollyea, D.A.; Fathi, A.T.; Roboz, G.J.; Altman, J.K.; Stone, R.M.; DeAngelo, D.J.; Levine, R.L.; Flinn, I.W.; et al. Enasidenib in mutant IDH2 relapsed or refractory acute myeloid leukemia. Blood 2017, 130, 722-731. [CrossRef]

16. Roboz, G.J.; DiNardo, C.D.; Stein, E.M.; de Botton, S.; Mims, A.S.; Prince, G.T.; Altman, J.K.; Arellano, M.L.; Donnellan, W.B.; Erba, H.P.; et al. Ivosidenib (AG-120) Induced Durable Remissions and Transfusion Independence in Patients with IDH1-Mutant Untreated AML: Results from a Phase 1 Dose Escalation and Expansion Study. Blood 2018, 132, 561. [CrossRef]

17. Tallman, M.S.; Wang, E.S.; Altman, J.K.; Appelbaum, F.R.; Bhatt, V.R.; Bixby, D.; Coutre, S.E.; Lima, M.D.; Fathi, A.T.; Fiorella, M.; et al. Acute Myeloid Leukemia, Version 3.2019, NCCN Clinical Practice Guidelines in Oncology. J. Natl. Compr. Cancer Netw. 2019, 17, 721. [CrossRef]

18. Stein, E.M.; Garcia-Manero, G.; Rizzieri, D.A.; Tibes, R.; Berdeja, J.G.; Savona, M.R.; Jongen-Lavrenic, M.; Altman, J.K.; Thomson, B.; Blakemore, S.J.; et al. The DOT1L inhibitor pinometostat reduces H3K79 methylation and has modest clinical activity in adult acute leukemia. Blood 2018, 131, 2661-2669. [CrossRef]

19. Klaus, C.R.; Iwanowicz, D.; Johnston, D.; Campbell, C.A.; Smith, J.J.; Moyer, M.P.; Copeland, R.A.; Olhava, E.J.; Scott, M.P.; Pollock, R.M.; et al. DOT1L inhibitor EPZ-5676 displays synergistic antiproliferative activity in combination with standard of care drugs and hypomethylating agents in MLL-rearranged leukemia cells. J. Pharm. Exp. Ther. 2014, 350, 646-656. [CrossRef]

20. Goldberg, S.L.; Fenaux, P.; Craig, M.D.; Gyan, E.; Lister, J.; Kassis, J.; Pigneux, A.; Schiller, G.J.; Jung, J.; Jane Leonard, E.; et al. An exploratory phase 2 study of investigational Aurora A kinase inhibitor alisertib (MLN8237) in acute myelogenous leukemia and myelodysplastic syndromes. Leuk. Res. Rep. 2014, 3, 58-61. [CrossRef]

21. Brunner, A.M.; Blonquist, T.M.; DeAngelo, D.J.; McMasters, M.; Winer, E.S.; Hobbs, G.S.; Amrein, P.C.; Hock, H.; Steensma, D.P.; Garcia, J.S.; et al. Phase II Clinical Trial of Alisertib, an Aurora a Kinase Inhibitor, in Combination with Induction Chemotherapy in High-Risk, Untreated Patients with Acute Myeloid Leukemia. Blood 2018, 132, 766. [CrossRef]

22. Goldenson, B.; Crispino, J.D. The aurora kinases in cell cycle and leukemia. Oncogene 2015, 34, 537-545. [CrossRef] [PubMed]

23. Steegmaier, M.; Hoffmann, M.; Baum, A.; Lenart, P.; Petronczki, M.; Krssak, M.; Gurtler, U.; Garin-Chesa, P.; Lieb, S.; Quant, J.; et al. BI 2536, a potent and selective inhibitor of polo-like kinase 1, inhibits tumor growth in vivo. Curr. Biol. 2007, 17, 316-322. [CrossRef] [PubMed]

24. Zeidan, A.M.; Becker, P.; Spira, A.I.; Patel, P.A.; Schiller, G.J.; Tsai, M.L.; Lin, T.L.; Ridinger, M.; Erlander, M.; Silberman, S.L.; et al. Abstract CT102: Phase Ib safety, preliminary anti-leukemic activity and biomarker analysis of the polo-like kinase 1 (PLK1) inhibitor, onvansertib, in combination with low-dose cytarabine or decitabine in patients with relapsed or refractory acute myeloid leukemia. Cancer Res. 2019, 79, CT102. [CrossRef]

25. Zahreddine, H.A.; Culjkovic-Kraljacic, B.; Assouline, S.; Gendron, P.; Romeo, A.A.; Morris, S.J.; Cormack, G.; Jaquith, J.B.; Cerchietti, L.; Cocolakis, E.; et al. The sonic hedgehog factor GLI1 imparts drug resistance through inducible glucuronidation. Nature 2014, 511, 90-93. [CrossRef]

26. Li, X.; Chen, F.; Zhu, Q.; Ding, B.; Zhong, Q.; Huang, K.; Jiang, X.; Wang, Z.; Yin, C.; Zhu, Y.; et al. Gli-1/PI3K/AKT/NF-kB pathway mediates resistance to radiation and is a target for reversion of responses in refractory acute myeloid leukemia cells. Oncotarget 2016, 7, 33004-33015. [CrossRef]

27. Cortes, J.E.; Heidel, F.H.; Hellmann, A.; Fiedler, W.; Smith, B.D.; Robak, T.; Montesinos, P.; Pollyea, D.A.; DesJardins, P.; Ottmann, O.; et al. Randomized comparison of low dose cytarabine with or without glasdegib in patients with newly diagnosed acute myeloid leukemia or high-risk myelodysplastic syndrome. Leukemia 2019, 33, 379-389. [CrossRef] [PubMed]

28. Itoh, K.; Yoshioka, K.; Akedo, H.; Uehata, M.; Ishizaki, T.; Narumiya, S. An essential part for Rho-associated kinase in the transcellular invasion of tumor cells. Nat. Med. 1999, 5, 221-225. [CrossRef]

29. Somlyo, A.V.; Bradshaw, D.; Ramos, S.; Murphy, C.; Myers, C.E.; Somlyo, A.P. Rho-Kinase Inhibitor Retards Migration and in Vivo Dissemination of Human Prostate Cancer Cells. Biochem. Biophys. Res. Commun. 2000, 269, 652-659. [CrossRef]

30. Sebbagh, M.; Renvoizé, C.; Hamelin, J.; Riché, N.; Bertoglio, J.; Bréard, J. Caspase-3-mediated cleavage of ROCK I induces MLC phosphorylation and apoptotic membrane blebbing. Nat. Cell Biol. 2001, 3, 346-352. [CrossRef] [PubMed]

31. Coleman, M.L.; Sahai, E.A.; Yeo, M.; Bosch, M.; Dewar, A.; Olson, M.F. Membrane blebbing during apoptosis results from caspase-mediated activation of ROCK I. Nat. Cell Biol. 2001, 3, 339-345. [CrossRef]

32. Lambert, J.; Pautas, C.; Terre, C.; Raffoux, E.; Turlure, P.; Caillot, D.; Legrand, O.; Thomas, X.; Gardin, C.; Gogat-Marchant, K.; et al. Gemtuzumab ozogamicin for de novo acute myeloid leukemia: Final efficacy and safety updates from the open-label, phase III ALFA-0701 trial. Haematologica 2019, 104, 113-119. [CrossRef]

33. Majeti, R.; Chao, M.P.; Alizadeh, A.A.; Pang, W.W.; Jaiswal, S.; Gibbs, K.D., Jr.; van Rooijen, N.; Weissman, I.L. CD47 is an adverse prognostic factor and therapeutic antibody target on human acute myeloid leukemia stem cells. Cell 2009, 138, 286-299. [CrossRef]

34. Sallman, D.A.; Asch, A.S.; Al Malki, M.M.; Lee, D.J.; Donnellan, W.B.; Marcucci, G.; Kambhampati, S.; Daver, N.G.; Garcia-Manero, G.; Komrokji, R.S.; et al. The First-in-Class Anti-CD47 Antibody Magrolimab (5F9) in Combination with Azacitidine Is Effective in MDS and AML Patients: Ongoing Phase 1b Results. Blood 2019, 134, 569. [CrossRef] 
35. Daver, N.; Garcia-Manero, G.; Basu, S.; Boddu, P.C.; Alfayez, M.; Cortes, J.E.; Konopleva, M.; Ravandi-Kashani, F.; Jabbour, E.; Kadia, T.; et al. Efficacy, Safety, and Biomarkers of Response to Azacitidine and Nivolumab in Relapsed/Refractory Acute Myeloid Leukemia: A Nonrandomized, Open-Label, Phase II Study. Cancer Discov. 2019, 9, 370-383. [CrossRef]

36. Liu, L.; Li, G.; Li, Q.; Jin, Z.; Zhang, L.; Zhou, J.; Hu, X.; Zhou, T.; Chen, J.; Gao, N. Triptolide induces apoptosis in human leukemia cells through caspase-3-mediated ROCK1 activation and MLC phosphorylation. Cell Death Dis. 2013, 4, e941. [CrossRef] [PubMed]

37. Amano, M.; Nakayama, M.; Kaibuchi, K. Rho-kinase/ROCK: A key regulator of the cytoskeleton and cell polarity. Cytoskeleton 2010, 67, 545-554. [CrossRef] [PubMed]

38. Porazinski, S.; Parkin, A.; Pajic, M. Rho-ROCK Signaling in Normal Physiology and as a Key Player in Shaping the Tumor Microenvironment. In Tumor Microenvironment: Signaling Pathways—Part A; Birbrair, A., Ed.; Springer International Publishing: Cham, Switzerland, 2020; pp. 99-127.

39. Wei, L.; Surma, M.; Shi, S.; Lambert-Cheatham, N.; Shi, J. Novel Insights into the Roles of Rho Kinase in Cancer. Arch. Immunol. Ther. Exp. 2016, 64, 259-278. [CrossRef] [PubMed]

40. Riento, K.; Ridley, A.J. Rocks: Multifunctional kinases in cell behaviour. Nat. Rev. Mol. Cell Biol. 2003, 4, 446-456. [CrossRef]

41. Rath, N.; Olson, M.F. Rho-associated kinases in tumorigenesis: Re-considering ROCK inhibition for cancer therapy. EMBO Rep. 2012, 13, 900-908. [CrossRef]

42. Mertsch, S.; Kramer, O.H. The interplay between histone deacetylases and rho kinases is important for cancer and neurodegeneration. Cytokine Growth Factor Rev. 2017, 37, 29-45. [CrossRef]

43. Loirand, G. Rho Kinases in Health and Disease: From Basic Science to Translational Research. Pharm. Rev. 2015, 67, 1074-1095. [CrossRef]

44. Mali, R.S.; Ramdas, B.; Ma, P.; Shi, J.; Munugalavadla, V.; Sims, E.; Wei, L.; Vemula, S.; Nabinger, S.C.; Goodwin, C.B.; et al. Rho kinase regulates the survival and transformation of cells bearing oncogenic forms of KIT, FLT3, and BCR-ABL. Cancer Cell 2011, 20, 357-369. [CrossRef]

45. Hartmann, S.; Ridley, A.J.; Lutz, S. The Function of Rho-Associated Kinases ROCK1 and ROCK2 in the Pathogenesis of Cardiovascular Disease. Front. Pharm. 2015, 6, 276. [CrossRef] [PubMed]

46. Liao, J.K.; Seto, M.; Noma, K. Rho kinase (ROCK) inhibitors. J. Cardiovasc. Pharm. 2007, 50, 17-24. [CrossRef]

47. Defert, O.; Boland, S. Rho kinase inhibitors: A patent review (2014-2016). Expert Opin. Ther. Pat. 2017, 27, 507-515. [CrossRef] [PubMed]

48. Wilkinson, S.; Paterson, H.F.; Marshall, C.J. Cdc42-MRCK and Rho-ROCK signalling cooperate in myosin phosphorylation and cell invasion. Nat. Cell Biol. 2005, 7, 255-261. [CrossRef] [PubMed]

49. Heikkila, T.; Wheatley, E.; Crighton, D.; Schroder, E.; Boakes, A.; Kaye, S.J.; Mezna, M.; Pang, L.; Rushbrooke, M.; Turnbull, A.; et al. Co-crystal structures of inhibitors with MRCKbeta, a key regulator of tumor cell invasion. PLoS ONE 2011, 6, e24825. [CrossRef]

50. Kale, V.P.; Hengst, J.A.; Desai, D.H.; Dick, T.E.; Choe, K.N.; Colledge, A.L.; Takahashi, Y.; Sung, S.S.; Amin, S.G.; Yun, J.K. A novel selective multikinase inhibitor of ROCK and MRCK effectively blocks cancer cell migration and invasion. Cancer Lett. 2014, 354, 299-310. [CrossRef] [PubMed]

51. Annageldiyev, C.; Gowda, K.; Patel, T.; Bhattacharya, P.; Tan, S.F.; Iyer, S.; Desai, D.; Dovat, S.; Feith, D.J.; Loughran, T.P., Jr.; et al. The novel Isatin analog KS99 targets stemness markers in acute myeloid leukemia. Haematologica 2020, 105, 687-696. [CrossRef]

52. Annageldiyev, C.; Tan, S.F.; Thakur, S.; Dhanyamraju, P.K.; Ramisetti, S.R.; Bhadauria, P.; Schick, J.; Zeng, Z.; Sharma, V.; Dunton, W.; et al. The PI3K/AKT Pathway Inhibitor ISC-4 Induces Apoptosis and Inhibits Growth of Leukemia in Preclinical Models of Acute Myeloid Leukemia. Front. Oncol. 2020, 10, 393. [CrossRef]

53. Schneider, C.A.; Rasband, W.S.; Eliceiri, K.W. NIH Image to ImageJ: 25 years of image analysis. Nat. Methods 2012, 9, 671-675. [CrossRef]

54. FlowJo ${ }^{\mathrm{TM}}$ Software for Mac, 10.8; Becton, Dickinson and Company: Ashland, OR, USA, 2019.

55. Short, N.J.; Konopleva, M.; Kadia, T.M.; Borthakur, G.; Ravandi, F.; DiNardo, C.D.; Daver, N. Advances in the Treatment of Acute Myeloid Leukemia: New Drugs and New Challenges. Cancer Discov. 2020, 10, 506-525. [CrossRef]

56. Kantarjian, H.M.; Kadia, T.M.; DiNardo, C.D.; Welch, M.A.; Ravandi, F. Acute myeloid leukemia: Treatment and research outlook for 2021 and the MD Anderson approach. Cancer 2021, 127, 1186-1207. [CrossRef]

57. Fernandez, H.F.; Sun, Z.; Yao, X.; Litzow, M.R.; Luger, S.M.; Paietta, E.M.; Racevskis, J.; Dewald, G.W.; Ketterling, R.P.; Bennett, J.M.; et al. Anthracycline dose intensification in acute myeloid leukemia. N. Engl. J. Med. 2009, 361, 1249-1259. [CrossRef]

58. Lowenberg, B.; Ossenkoppele, G.J.; van Putten, W.; Schouten, H.C.; Graux, C.; Ferrant, A.; Sonneveld, P.; Maertens, J.; JongenLavrencic, M.; von Lilienfeld-Toal, M.; et al. High-dose daunorubicin in older patients with acute myeloid leukemia. N. Engl. J. Med. 2009, 361, 1235-1248. [CrossRef]

59. Wermke, M.; Camgoz, A.; Paszkowski-Rogacz, M.; Thieme, S.; von Bonin, M.; Dahl, A.; Platzbecker, U.; Theis, M.; Ehninger, G.; Brenner, S.; et al. RNAi profiling of primary human AML cells identifies ROCK1 as a therapeutic target and nominates fasudil as an antileukemic drug. Blood 2015, 125, 3760-3768. [CrossRef]

60. Li, B.; Zhao, W.D.; Tan, Z.M.; Fang, W.G.; Zhu, L.; Chen, Y.H. Involvement of Rho/ROCK signalling in small cell lung cancer migration through human brain microvascular endothelial cells. FEBS Lett. 2006, 580, 4252-4260. [CrossRef] 
61. Chin, V.T.; Nagrial, A.M.; Chou, A.; Biankin, A.V.; Gill, A.J.; Timpson, P.; Pajic, M. Rho-associated kinase signalling and the cancer microenvironment: Novel biological implications and therapeutic opportunities. Expert Rev. Mol. Med. 2015, 17, e17. [CrossRef]

62. Yang, Q.; Crispino, J.D.; Wen, Q.J. Kinase signaling and targeted therapy for primary myelofibrosis. Exp. Hematol. 2017, 48, 32-38. [CrossRef]

63. Burthem, J.; Rees-Unwin, K.; Mottram, R.; Adams, J.; Lucas, G.S.; Spooncer, E.; Whetton, A.D. The rho-kinase inhibitors Y-27632 and fasudil act synergistically with imatinib to inhibit the expansion of ex vivo CD34(+) CML progenitor cells. Leukemia 2007, 21, 1708-1714. [CrossRef]

64. Liu, G.J.; Wang, Z.J.; Wang, Y.F.; Xu, L.L.; Wang, X.L.; Liu, Y.; Luo, G.J.; He, G.H.; Zeng, Y.J. Systematic assessment and metaanalysis of the efficacy and safety of fasudil in the treatment of cerebral vasospasm in patients with subarachnoid hemorrhage. Eur. J. Clin. Pharm. 2012, 68, 131-139. [CrossRef]

65. Winkler, F.; Kozin, S.V.; Tong, R.T.; Chae, S.S.; Booth, M.F.; Garkavtsev, I.; Xu, L.; Hicklin, D.J.; Fukumura, D.; di Tomaso, E.; et al. Kinetics of vascular normalization by VEGFR2 blockade governs brain tumor response to radiation: Role of oxygenation, angiopoietin-1, and matrix metalloproteinases. Cancer Cell 2004, 6, 553-563. [CrossRef]

66. Ito, M.; Nakano, T.; Erdodi, F.; Hartshorne, D.J. Myosin phosphatase: Structure, regulation and function. Mol. Cell. Biochem. 2004, 259, 197-209. [CrossRef]

67. Patel, R.A.; Liu, Y.; Wang, B.; Li, R.; Sebti, S.M. Identification of novel ROCK inhibitors with anti-migratory and anti-invasive activities. Oncogene 2014, 33, 550-555. [CrossRef]

68. Liu, S.; Goldstein, R.H.; Scepansky, E.M.; Rosenblatt, M. Inhibition of Rho-Associated Kinase Signaling Prevents Breast Cancer Metastasis to Human Bone. Cancer Res. 2009, 69, 8742-8751. [CrossRef]

69. Nakabayashi, H.; Shimizu, K. HA1077, a Rho kinase inhibitor, suppresses glioma-induced angiogenesis by targeting the RhoROCK and the mitogen-activated protein kinase kinase/extracellular signal-regulated kinase (MEK/ERK) signal pathways. Cancer Sci. 2011, 102, 393-399. [CrossRef]

70. Nakajima, M.; Hayashi, K.; Egi, Y.; Katayama, K.-I.; Amano, Y.; Uehata, M.; Ohtsuki, M.; Fujii, A.; Oshita, K.-i.; Kataoka, H.; et al. Effect of Wf-536, a novel ROCK inhibitor, against metastasis of B16 melanoma. Cancer Chemother. Pharmacol. 2003, 52, 319-324. [CrossRef]

71. Routhier, A.; Astuccio, M.; Lahey, D.; Monfredo, N.; Johnson, A.; Callahan, W.; Partington, A.; Fellows, K.; Ouellette, L.; Zhidro, S.; et al. Pharmacological inhibition of Rho-kinase signaling with Y-27632 blocks melanoma tumor growth. Oncol. Rep. 2010, 23, 861-867. [CrossRef]

72. Somlyo, A.V.; Phelps, C.; Dipierro, C.; Eto, M.; Read, P.; Barrett, M.; Gibson, J.J.; Burnitz, M.C.; Myers, C.; Somlyo, A.P. Rho kinase and matrix metalloproteinase inhibitors cooperate to inhibit angiogenesis and growth of human prostate cancer xenotransplants. FASEB J. 2003, 17, 223-234. [CrossRef]

73. Ying, H.; Biroc, S.L.; Li, W.-w.; Alicke, B.; Xuan, J.-A.; Pagila, R.; Ohashi, Y.; Okada, T.; Kamata, Y.; Dinter, H. The Rho kinase inhibitor fasudil inhibits tumor progression in human and rat tumor models. Mol. Cancer Ther. 2006, 5, 2158-2164. [CrossRef]

74. DiNardo, C.D.; Pratz, K.; Pullarkat, V.; Jonas, B.A.; Arellano, M.; Becker, P.S.; Frankfurt, O.; Konopleva, M.; Wei, A.H.; Kantarjian, H.M.; et al. Venetoclax combined with decitabine or azacitidine in treatment-naive, elderly patients with acute myeloid leukemia. Blood 2019, 133, 7-17. [CrossRef]

75. Wei, A.H.; Strickland, S.A., Jr.; Hou, J.Z.; Fiedler, W.; Lin, T.L.; Walter, R.B.; Enjeti, A.; Tiong, I.S.; Savona, M.; Lee, S.; et al. Venetoclax Combined With Low-Dose Cytarabine for Previously Untreated Patients With Acute Myeloid Leukemia: Results From a Phase Ib/II Study. J. Clin. Oncol. 2019, 37, 1277-1284. [CrossRef]

76. Onishi, C.; Mori-Kimachi, S.; Hirade, T.; Abe, M.; Taketani, T.; Suzumiya, J.; Sugimoto, T.; Yamaguchi, S.; Kapur, R.; Fukuda, S. Internal tandem duplication mutations in FLT3 gene augment chemotaxis to Cxcl12 protein by blocking the down-regulation of the Rho-associated kinase via the Cxcl12/Cxcr4 signaling axis. J. Biol. Chem. 2014, 289, 31053-31065. [CrossRef]

77. Fiedler, W.; Mesters, R.; Tinnefeld, H.; Loges, S.; Staib, P.; Duhrsen, U.; Flasshove, M.; Ottmann, O.G.; Jung, W.; Cavalli, F.; et al. A phase 2 clinical study of SU5416 in patients with refractory acute myeloid leukemia. Blood 2003, 102, 2763-2767. [CrossRef]

78. Smith, B.D.; Levis, M.; Beran, M.; Giles, F.; Kantarjian, H.; Berg, K.; Murphy, K.M.; Dauses, T.; Allebach, J.; Small, D. Single-agent CEP-701, a novel FLT3 inhibitor, shows biologic and clinical activity in patients with relapsed or refractory acute myeloid leukemia. Blood 2004, 103, 3669-3676. [CrossRef]

79. Stirewalt, D.L.; Radich, J.P. The role of FLT3 in haematopoietic malignancies. Nat. Rev. Cancer 2003, 3, 650-665. [CrossRef]

80. Gilliland, D.G.; Griffin, J.D. The roles of FLT3 in hematopoiesis and leukemia. Blood 2002, 100, 1532-1542. [CrossRef]

81. Whitman, S.P.; Archer, K.J.; Feng, L.; Baldus, C.; Becknell, B.; Carlson, B.D.; Carroll, A.J.; Mrozek, K.; Vardiman, J.W.; George, S.L.; et al. Absence of the wild-type allele predicts poor prognosis in adult de novo acute myeloid leukemia with normal cytogenetics and the internal tandem duplication of FLT3: A cancer and leukemia group B study. Cancer Res. 2001, 61, 7233-7239.

82. Frohling, S.; Schlenk, R.F.; Breitruck, J.; Benner, A.; Kreitmeier, S.; Tobis, K.; Dohner, H.; Dohner, K.; leukemia, A.M.L.S.G.U.A.m. Prognostic significance of activating FLT3 mutations in younger adults (16 to 60 years) with acute myeloid leukemia and normal cytogenetics: A study of the AML Study Group Ulm. Blood 2002, 100, 4372-4380. [CrossRef]

83. Müller, J.P.; Schmidt-Arras, D. Novel Approaches to Target Mutant FLT3 Leukaemia. Cancers 2020, 12, 2806. [CrossRef] [PubMed]

84. Nervi, B.; Ramirez, P.; Rettig, M.P.; Uy, G.L.; Holt, M.S.; Ritchey, J.K.; Prior, J.L.; Piwnica-Worms, D.; Bridger, G.; Ley, T.J.; et al Chemosensitization of acute myeloid leukemia (AML) following mobilization by the CXCR4 antagonist AMD3100. Blood 2009, 113, 6206-6214. [CrossRef] [PubMed] 
85. Uy, G.L.; Rettig, M.P.; Motabi, I.H.; McFarland, K.; Trinkaus, K.M.; Hladnik, L.M.; Kulkarni, S.; Abboud, C.N.; Cashen, A.F.; Stockerl-Goldstein, K.E.; et al. A phase 1/2 study of chemosensitization with the CXCR4 antagonist plerixafor in relapsed or refractory acute myeloid leukemia. Blood 2012, 119, 3917-3924. [CrossRef] [PubMed]

86. Zeng, Z.; Shi, Y.X.; Samudio, I.J.; Wang, R.Y.; Ling, X.; Frolova, O.; Levis, M.; Rubin, J.B.; Negrin, R.R.; Estey, E.H.; et al. Targeting the leukemia microenvironment by CXCR4 inhibition overcomes resistance to kinase inhibitors and chemotherapy in AML. Blood 2009, 113, 6215-6224. [CrossRef] 